\title{
Evolution of the Southern Annular Mode during the last millennium
}

Nerilie J. Abram ${ }^{1,2^{*}}$, Robert Mulvaney ${ }^{1}$, Françoise Vimeux ${ }^{3}$, Steven J. Phipps ${ }^{4}$, John Turner $^{1}$ and Matthew H. England ${ }^{4}$

1. British Antarctic Survey, Natural Environment Research Council, Cambridge CB3 OET, United Kingdom

2. Research School of Earth Sciences, Australian National University, Canberra ACT 0200, Australia

3. Institut de Recherche pour le Développement, Laboratoire HydroSciences Montpellier et Laboratoire des

Sciences du Climat et de l'Environment, 91191 Gif-sur-Yvette, France

4. Climate Change Research Centre and ARC Centre of Climate System Science, University of New South

Wales, Sydney NSW 2052, Australia

*email: nerilie.abram@anu.edu.au

The Southern Annular Mode (SAM) is the primary pattern of climate variability in the Southern Hemisphere ${ }^{1,2}$, influencing latitudinal rainfall distribution and temperatures from the subtropics to Antarctica. The positive summer trend in the SAM over recent decades is widely-attributed to stratospheric ozone depletion ${ }^{2}$, however the brevity of observational records from Antarctica ${ }^{1}-$ one of the core zones that defines SAM variability - limits our understanding of long-term SAM behaviour. Here we reconstruct annual-mean changes in the SAM since 1000AD using, for the first time, proxy records that encompass the full mid-latitude to polar domain across the Drake Passage sector. We find that the SAM has undergone a progressive shift towards its positive phase since the $15^{\text {th }}$ Century, causing cooling of the main Antarctic continent at the same time that the Antarctic Peninsula has warmed. The positive trend in the SAM since 1940AD is reproduced by multi-model climate simulations forced with rising greenhouse gas levels and later ozone depletion, and the long-term average SAM Index is now at its highest level for at least the last $\mathbf{1 0 0 0}$ years. Reconstructed SAM trends prior to the $20^{\text {th }}$ Century are more prominent than those in radiative-forcing climate experiments, and may be associated with a teleconnected response to tropical Pacific climate. Our findings imply that predictions of further greenhousedriven increases in the SAM over the coming century ${ }^{3}$ also need to account for the possibility of opposing effects from tropical Pacific climate changes. 
Warming of the polar-regions has global implications for sea level rise and climate change feedback processes such as decreased planetary albedo and the release of naturally-stored carbon reservoirs. High latitude amplification of global warming trends is clearly observed across the $\operatorname{Arctic}^{4,5}$. In contrast, Antarctica is the only continental region where long-term cooling over the last 2000 years has not yet been reversed to climate warming ${ }^{5}$. Yet some regions of Antarctica have warmed significantly over the last $\sim 50$ years, with the Antarctic Peninsula and parts of West Antarctica displaying the most rapid temperature increases in the Southern Hemisphere ${ }^{6,7}$. Understanding these regional responses of Antarctic temperature to recent climate change requires an improved characterisation of natural and anthropogenically-driven changes in Southern Hemisphere climate variability.

In this study we use the James Ross Island (JRI) ice core from the northern Antarctic Peninsula ${ }^{7-9}$ $\left(64.2^{\circ} \mathrm{S}, 57.7^{\circ} \mathrm{W}\right.$; Fig. 1), along with other published temperature-sensitive proxies ${ }^{5}$, to reconstruct Southern Annular Mode (SAM) variability since 1000AD. The SAM can be defined by the zonal mean atmospheric pressure difference between the mid-latitudes $\left(\sim 40^{\circ} \mathrm{S}\right)$ and Antarctica $\left(\sim 65^{\circ} \mathrm{S}\right)^{1}$. The positive phase of the SAM is associated with low pressure anomalies over Antarctica and high pressure anomalies over the mid-latitudes, and this enhanced atmospheric pressure gradient results in strengthening and poleward contraction of the Southern Hemisphere westerly jet stream $^{1}$. The mountainous geographic barrier of the Antarctic Peninsula makes temperature variability in this region particularly sensitive to the strength of the westerly winds passing through Drake Passage. As such, JRI is a key location for documenting SAM-related climate variability (Fig. 1b) and previous work ${ }^{8,9}$ has demonstrated that the water isotope-derived temperature record from the JRI ice core is significantly correlated with observational indices of the SAM ${ }^{1,10}$.

The JRI temperature record since 1000AD has an inverse correlation with the PAGES2k reconstruction of continental Antarctic temperature ${ }^{5}$ (Fig. 1a). This opposing temperature history between the Antarctic Peninsula and the main Antarctic continent is consistent with the spatial response of surface air temperatures to SAM variability (Fig. 1b), and is statistically significant at annual to multi-decadal timescales (Table 1). The JRI temperature record also displays similarities to the PAGES2k South American temperature reconstruction ${ }^{5}$ that may indicate a shared climate forcing, although the positive correlation between the two datasets is not statistically significant 
(Table 1). However, in their long-term evolution the South American and JRI reconstructions both indicate that the coolest 50-year interval of the last millennium occurred at 1410-1460AD, with progressive phases of warming since that time (Fig. 1a).

We combine the JRI temperature record with the PAGES2k compilations of South American and Antarctic temperature-sensitive proxies to derive a weighted composite-plus-scale ${ }^{11,12}$ reconstruction of the SAM Index during the last millennium (Fig. 2; Methods; Supplementary Table 1; Supplementary Figures 1-3). Together, the proxies capture climate information in all seasons and span the mid-latitude to polar domains where the SAM has a major influence on temperature (Fig. 1b). Multi-model climate simulations indicate that the regional temperature patterns associated with modern-day SAM variability persisted through the last millennium (Supplementary Figure 4), supporting the use of the proxy network to reconstruct the long-term history of the SAM. We restrict the mid-latitude proxy data to the South American continent to produce a reconstruction that is specifically related to SAM variability in the Drake Passage sector. We do this because although the SAM is classically described as a zonally-symmetric climate feature, its variability and tropical climate interactions have seasonal asymmetries that are particularly strong in the South Pacific and Antarctic Peninsula regions ${ }^{13-15}$. Analysis with ERA-Interim ${ }^{16}$ data since 1979AD and climate simulations spanning the last millennium demonstrates, however, that at annual average and longer timescales SAM variability in the Drake Passage sector is highly representative of the circumpolar mean state of the SAM (Supplementary Figures 5-6).

Our SAM reconstruction for the last millennium shows that the most extreme negative phase of the SAM occurred during the $15^{\text {th }}$ Century (Fig. 2c, Fig. 3a). Other proxy-based assessments support a minimum in the SAM at this time. For example, an epoch-analysis of proxies for Southern Hemisphere circulation identified persistent negative SAM conditions between $1300-1450 A D^{17}$, while a 600-year reconstruction based on mid-latitude tree growth in New Zealand and South America documented the most extreme negative summer SAM values at $\sim 1470$ AD ${ }^{18}$ (Fig 3b). A 700year winter sea salt record from the Law Dome ice core also shows a tendency for more positive SAM conditions since $\sim 1500 A D^{19}$, and an increase in the frequency of severe droughts in the Central Andes over the last six centuries has been attributed to southward contraction of the westerly storm tracks ${ }^{20}$ (Supplementary Figure 7). Together these records demonstrate that the positive 
trend in SAM since the $15^{\text {th }}$ Century is a robust feature that impacted mid-latitude and polar sites around the full SAM domain.

Our reconstruction indicates that the transition to a more positive SAM after the $15^{\text {th }}$ Century occurred in two stages. First, a progressive increase in the SAM occurred during the $~ 300$ years spanning the $16^{\text {th }}$ to $18^{\text {th }}$ Centuries. This trend then reversed during the $19^{\text {th }}$ Century, before recommencing in the $20^{\text {th }}$ century (Fig. $2 \mathrm{c}$ ). Trend analysis tests on our proxy-based reconstruction indicate that the recent positive trend in the annual SAM Index has been significant since $1940 \mathrm{AD}$ (Supplementary Figure 8a).

A valuable tool to assess proxy-model agreement on past SAM behavior are the "last millennium" transient climate model simulations performed as part of the $5^{\text {th }}$ Coupled Model Intercomparison Project (CMIP5) ${ }^{21,22}$ (methods; Supplementary Table 2). The ensemble mean of eight climate models indicates that the positive SAM trend during the $20^{\text {th }}$ Century is a feature that is consistently produced in experiments with transient radiative forcings (Fig. 3c,d). The positive trend in the modeled SAM Index since 1940AD has an equivalent magnitude (+0.3 units/decade) to our proxybased reconstruction, although the precise initiation point for the $20^{\text {th }}$ Century SAM increase is not as well-constrained in the CMIP5 ensemble mean (Supplementary Figure 8). This is because the CMIP5 simulations do not reproduce the negative SAM trend during the $19^{\text {th }}$ Century that is observed in the proxy-derived reconstruction. The CMIP5 ensemble mean also displays a much weaker positive trend in the SAM Index during the $16^{\text {th }}$ to $18^{\text {th }}$ Centuries (+0.006 units/decade) than indicated by our reconstruction (+0.1 units/decade). Thus, while proxy-model agreement on SAM trends in the $20^{\text {th }}$ century is reasonably good, there are discrepancies in the structure and magnitude of SAM changes prior to this time.

The influence of different radiative forcing mechanisms on the evolution of SAM is investigated using multiple simulations of the last millennium with a coupled climate model ${ }^{23}$ (Methods; Fig. 3e). No long-term trend in the SAM is observed in experiments conducted using only orbital forcing. The addition of anthropogenic greenhouse gases causes a positive shift in the ensemble mean SAM Index that exceeds the $+2 \sigma$ level of unforced SAM variability during the $20^{\text {th }}$ Century. This is in 
agreement with other model-based studies that find increased greenhouse gas levels cause a positive shift in the SAM due to enhanced meridional temperature gradients in the Southern Hemisphere $^{2,3}$. It is also consistent with the hypothesis that the early-mid $20^{\text {th }}$ century commencement of Antarctic Peninsula warming is not explained by ozone-forced increases of the SAM alone ${ }^{9}$.

The addition of solar forcing to the coupled climate model simulations produces an increasing trend in the SAM Index over the $16^{\text {th }}$ to $18^{\text {th }}$ Centuries (Fig. 3e). This could be explained by increasing solar irradiance after the $15^{\text {th }}$ Century Spörer minimum, as multi-model assessments of CMIP5 historical simulations (since 1861 AD) have determined that changes in solar irradiance exert a small positive forcing on the $\mathrm{SAM}^{3}$. However, the modeled SAM trend during the $16^{\text {th }}$ to $18^{\text {th }}$ Centuries is not significant relative to the distribution of trends in a 10,000-year unforced simulation of the same model. The large pre-industrial trends in SAM that are suggested by proxy records may thus imply that the SAM is more responsive to direct solar forcing than indicated by current climate simulations ${ }^{3}$, or that the magnitude of solar irradiance changes applied in the last millennium simulations is too $\mathrm{low}^{24,25}$. Further modeling studies using the full range of solar irradiance change estimates ${ }^{25}$ may help to clarify the impact that past solar changes had on the SAM. Alternately, it is possible that proxy-based reconstructions overestimate the magnitude of long-term changes in the SAM, or that the long-term changes in the SAM prior to anthropogenic greenhouse and ozone forcing were caused by internal variability or other physical process that cannot be resolved in radiative-forcing experiments.

Tropically-forced climate variability projects upon the high-latitude SAM pattern in the Drake Passage sector and may provide an additional mechanism to explain SAM trends during the last millennium. Instrumental studies have shown that EI Niño-Southern Oscillation (ENSO) variability in the tropical Pacific interacts via a Rossby wave-train with storm tracks in the South Pacific, such that El Niño (La Niña) events tend to cause cool (warm) conditions on the Antarctic Peninsula (Fig. 4a) and are associated with negative (positive) SAM states ${ }^{13-15}$. Using a recent multivariate reconstruction of SST in the Niño3.4 region since $1150 \mathrm{AD}^{26}$, a significant inverse correlation with our SAM reconstruction is obtained (Table 1). It is noted, however, that the Niño3.4 reconstruction also draws upon tree-growth records from South America. Therefore, we further verify that a significant 
inverse relationship exists between the Niño3.4 reconstruction and the independent JRI temperature record, located in the core region of ENSO-SAM teleconnections (Fig. 4; Table 1; Supplementary Figure 9). This suggests that the association of El Niño with negative SAM states is likely to be a persistent feature of the long-term interaction of these climate modes in the Antarctic Peninsula region.

If the ENSO-SAM relationship that exists on interannual timescales also influences the mean state of these climate modes, then the maximum in Niño3.4 SSTs during the $15^{\text {th }}$ century ${ }^{26}$ could have contributed to the SAM minimum at this time (Fig. 4b). The positive trend in Antarctic Peninsula temperature and the SAM during the $16^{\text {th }}$ to $18^{\text {th }}$ Centuries, and the reversal of these changes during the $19^{\text {th }}$ Century, also closely mirror changes in mean Niño3.4 SST. However, tropical Pacific climate appears to become a secondary influence on SAM trends during the $20^{\text {th }}$ Century, when the positive trend in Niño3.4 $\mathrm{SST}^{26}$ would be expected to have imposed a negative forcing on the mean state of SAM in the Drake Passage sector. A recent study highlighted that the positive trend in summer SAM during the $20^{\text {th }}$ Century has emerged above the opposing interannual forcing by $\mathrm{ENSO}^{27}$. Our findings extend this perspective over the last millennium, and suggest that tropical Pacific SST trends could have acted in a way that has muted the impact of increasing greenhouse gases and ozone depletion on SAM during the $20^{\text {th }}$ Century.

The long-term mean of the SAM Index is now at its highest positive value for at least the last 1000 years (Fig. 2c). Continued increases in atmospheric greenhouse gases are predicted to force the SAM further towards its positive phase over the coming century ${ }^{2,3}$. At the same time, stratospheric ozone recovery is expected to cause an opposing effect that may limit the magnitude of the positive greenhouse-driven SAM trend in summer ${ }^{2,3}$. However, summer temperatures along the Antarctic Peninsula are already sufficiently high to cause extensive surface ice melt ${ }^{9}$, and SAMdriven warming in other seasons may further increase the duration of the melt season along the Antarctic Peninsula ${ }^{28}$. Future greenhouse-driven increases in the SAM are also likely to have implications for limiting warming over continental Antarctica ${ }^{5}$ and for southward expansion of the dry sub-tropical climate belts ${ }^{18,20}$. In addition, the tropical Pacific is predicted to experience more extreme El Niño events during the coming century ${ }^{29}$ and our findings highlight the importance of being able to accurately model how their remote climate teleconnections will also impact the SAM. 


\section{Methods}

Proxy records. We use the deuterium isotope record from the James Ross Island ice core as a temperature proxy for the Antarctic Peninsula region ${ }^{8,9}$. Full details of the ice core site and isotope analysis can be found in ref. 7 . We use the JRI1 age model with annual layer chronology since 1807, as in ref. 9. Deuterium isotope measurements made at $10 \mathrm{~cm}$ resolution along the upper $300 \mathrm{~m}$ of the ice core correspond to better than annual resolution since $1111 \mathrm{AD}$, and were binned to produce annual ( January-December) averages. The 111 years between 1000-1110AD comprise 85 isotope measurements and interpolation was used to generate a pseudo-annual resolution record over this interval.

We also use temperature-sensitive proxy records for the Antarctic and South America continental regions ${ }^{5}$ to capture the full mid-latitude to polar expression of the SAM across the Drake Passage transect. The annually-resolved proxy datasets compiled as part of the PAGES2k database are published and publically available ${ }^{5}$. For the South American dataset we restrict our use to records south of $30^{\circ} \mathrm{S}$ and we do not use the four shortest records that are derived from instrumental sources. Details of the individual records used in this study and their correlation with the SAM are given in Supplementary Table 1.

Data available at ftp://ftp.ncdc.noaa.gov/pub/data/paleo/icecore/antarctica/james-ross-island/ and http://www.nature.com/ngeo/journal/v6/n5/full/ngeo1797.html

SAM reconstruction. The proxy records from the South America, Antarctic Peninsula and Antarctic continent regions (where SAM has a significant influence on temperature; Fig. 1b) were used to reconstruct an annual average SAM Index since 1000AD. We employ the widely-used Composite-Plus-Scale (CPS) methodology ${ }^{5,11,12}$ with nesting to account for the varying length of proxies making up the reconstruction. For each nest the contributing proxies were normalised relative to the 1957-1995AD calibration interval, which represents the interval of maximum overlap between the annual (Jan-Dec) Marshall-SAM Index (http://www.antarctica.ac.uk/met/gjma/sam.html) and the majority of the proxy network (Supplementary Table 1). The normalised proxy records were then combined with a weighting ${ }^{12}$ based on their correlation coefficient ( $r$ ) with the SAM during the calibration interval (Supplementary Table 1). The combined record was then scaled to match the mean and standard deviation of the instrumental SAM Index during the calibration interval. Finally, nests were spliced together to provide the full 1000-year SAM reconstruction. Alternate methods for carrying out the CPS reconstruction were explored and the primary findings discussed in this study are shown to be robust across different methodologies (Supplementary Figures 1-2).

For each proxy nest a 95\% confidence interval was defined as 1.96 times the standard deviation of the residuals of the SAM reconstruction from Marshall-SAM Index during the calibration interval. The reduction of error (RE) statistic was also calculated to test the performance of the reconstruction. The brevity of Antarctic instrumental records limits the ability to cross validate the SAM reconstruction using separate calibration and verification intervals ${ }^{18}$. Instead, we assess the significance of RE values by repeating 1000 CPS simulations where the proxy network was replaced by $A R(1)$ time series matching the length and lag-1 autocorrelation of the proxies, and we use the upper $95^{\text {th }}$ percentile to determine the critical $R E$ level $\left(R E_{c r i t}\right)$ for each proxy nest. We further verify the SAM reconstruction against the extended Fogt-SAM Index ${ }^{10}$ (http://polarmet.osu.edu/ACD/sam/sam_recon.html). To perform this 
assessment the four seasonal reconstructions of the Fogt-Index were averaged to estimate an annual (Dec-Nov) SAM, which was then scaled to match the variance of the Marshall-SAM Index from 1961-1990.

Model output. We use multi-model output from the subset of CMIP5 climate models that ran transient last millennium (past1000) simulations since $850 \mathrm{AD}^{21,22}$. Historical simulations from the same ensemble were used to extend the model output from 1850AD. The CMIP5 past1000 and historical experiments use transient radiative forcings that include orbital, solar, volcanic, greenhouse and ozone parameters as well as land use changes ${ }^{21,22}$. All data was accessed from the Earth System Grid Federation node (http://pcmdi9.IInl.gov/esgf-web-fe/), with the exception of the historical portion of the HadCM3 last millennium simulation (provided by Andrew Schurer, Edinburgh University) and the CSIRO Mk3L simulations. To assess the importance of different radiative forcing mechanisms, we used multiple simulations of the last 1500 years performed with the CSIRO Mk3L coupled climate model, as described in ref. 23. Supplementary Table 2 gives further details on the climate model datasets.

In this study we utilise monthly resolution mean sea level pressure (psl) data to calculate the zonal mean at $40^{\circ} \mathrm{S}$ and $65^{\circ} \mathrm{S}$. The model-generated data were averaged into January-December annuals to match the proxy data, normalised relative to the 1961-1990AD interval and differenced to generate a SAM Index ${ }^{1}$. We also use surface air temperature (tas) model output to examine SAM-temperature relationships at our proxy sites in the last millennium climate simulations (Supplementary Figure 4).

Data archive. The SAM reconstruction developed in this paper is archived with the World Data Center for Paleoclimatology (http://hurricane.ncdc.noaa.gov/pls/paleox/f?p=519:1:::::P1_STUDY_ID:16197). 


\section{Acknowledgements}

N.J.A. is supported by a Queen Elizabeth II fellowship awarded by the Australian Research Council (ARC DP110101161). This study contributes to ARC Discovery Project DP140102059 awarded to N.J.A. and R.M., and is part of the British Antarctic Survey “Polar Science for Planet Earth” programme funded by the Natural Environment Research Council. Modelling work using CSIRO Mk3L was supported by an award to S.J.P. of computational resources on the $\mathrm{NCI} N a t i o n a l$ Facility through the National Computational Merit Allocation Scheme. M.H.E. is supported by ARC Laureate Fellowship FL100100214. We thank Eric Wolff for discussions that improved the paper, and we gratefully acknowledge the efforts of the PAGES2k and CMIP5/PMIP3 communities in archiving the proxy synthesis and model products that were utilised in this study.

\section{Author Contributions}

N.J.A. conceived the study and performed the data analysis, with support from the other authors. All authors contributed to the discussion of ideas and writing of the paper.

\section{Additional information}

Supplementary information is available in the online version of the paper. Reprints and permissions information is available online at www.nature.com/reprints. Correspondence and requests for materials should be addressed to N.J.A.

\section{Competing financial interests}

The authors declare no competing financial interests. 


\section{References}

1 Marshall, G. J. Trends in the southern annular mode from observations and reanalyses. J. Clim. 16, 4134-4143 (2003).

2 Thompson, D. W. J. et al. Signatures of the Antarctic ozone hole in Southern Hemisphere surface climate change. Nature Geosci. 4, 741-749 (2011).

3 Gillett, N. P. \& Fyfe, J. C. Annular mode changes in the CMIP5 simulations. Geophys. Res. Lett. 40, 1189-1193, doi:10.1002/grl.50249 (2013).

4 Screen, J. A. \& Simmonds, I. The central role of diminishing sea ice in recent Arctic temperature amplification. Nature 464, 1334-1337, doi:10.1038/nature09051 (2010).

5 PAGES $2 \mathrm{k}$ consortium. Continental-scale temperature variability during the past two millennia. Nature Geosci. 6, 339-346, doi:10.1038/ngeo1797 (2013).

6 Bromwich, D. H. et al. Central West Antarctica among the most rapidly warming regions on Earth. Nature Geosci. 6, 139-144, doi:10.1038/ngeo1671 (2013).

7 Mulvaney, R. et al. Recent Antarctic Peninsula warming relative to Holocene climate and ice-shelf history. Nature 489, 141-144 (2012).

8 Abram, N. J., Mulvaney, R. \& Arrowsmith, C. Environmental signals in a highly resolved ice core from James Ross Island, Antarctica. J. Geophys. Res. 116, D20116, doi:10.1029/2011jd016147 (2011). Abram, N. J. et al. Acceleration of snow melt in an Antarctic Peninsula ice core during the twentieth century. Nature Geosci. 6, 404-411, doi:10.1038/ngeo1787 (2013). Fogt, R. L. et al. Historical SAM Variability. Part II: Twentieth-Century Variability and Trends from Reconstructions, Observations, and the IPCC AR4 Models. J. Clim. 22, 5346-5365, doi:10.1175/2009jcli2786.1 (2009).

11 Jones, P. D. et al. High-resolution palaeoclimatology of the last millennium: a review of current status and future prospects. The Holocene 19, 3-49, doi:10.1177/0959683608098952 (2009). Hegerl, G. C. et al. Detection of human influence on a new, validated 1500-year temperature reconstruction. J. Clim. 20, 650-666, doi:10.1175/JCLI4011.1 (2007).

Ding, Q. H., Steig, E. J., Battisti, D. S. \& Wallace, J. M. Influence of the Tropics on the Southern Annular Mode. J. Clim. 25, 6330-6348, doi:10.1175/jcli-d-11-00523.1 (2012).

14 Fogt, R. L., Jones, J. M. \& Renwick, J. Seasonal Zonal Asymmetries in the Southern Annular Mode and Their Impact on Regional Temperature Anomalies. J. Clim. 25, 6253-6270, doi:10.1175/jcli-d-11-00474.1 (2012). Fogt, R. L., Bromwich, D. H. \& Hines, K. M. Understanding the SAM influence on the South Pacific ENSO teleconnection. Clim. Dynam. 36, 1555-1576, doi:10.1007/s00382-010-0905-0 (2011).

16 Dee, D. P. et al. The ERA-Interim reanalysis: configuration and performance of the data assimilation system. $Q$. J. R. Meteorol. Soc. 137, 553-597, doi:10.1002/qj.828 (2011).

Goodwin, I. et al. A reconstruction of extratropical Indo-Pacific sea-level pressure patterns during the Medieval Climate Anomaly. Clim. Dynam., 1-23, doi:10.1007/s00382-013-1899-1 (2013). Villalba, R. et al. Unusual Southern Hemisphere tree growth patterns induced by changes in the Southern Annular Mode. Nature Geosci. 5, 793-798, doi:10.1038/ngeo1613 (2012). Goodwin, I. D., van Ommen, T. D., Curran, M. A. J. \& Mayewski, P. A. Mid latitude winter climate variability in the South Indian and southwest Pacific regions since 1300 AD. Clim. Dynam. 22, 783-794, doi:10.1007/s00382004-0403-3 (2004).

Christie, D. A. et al. Aridity changes in the Temperate-Mediterranean transition of the Andes since ad 1346 reconstructed from tree-rings. Clim. Dynam. 36, 1505-1521, doi:10.1007/s00382-009-0723-4 (2011). Taylor, K. E., Stouffer, R. J. \& Meehl, G. A. An overview of CMIP5 and the experiment design. Bull. Amer. Meteorol. Soc. 93, 485-498, doi:10.1175/bams-d-11-00094.1 (2012). Schmidt, G. A. et al. Climate forcing reconstructions for use in PMIP simulations of the last millennium (v1.0). Geosci. Model Dev. 4, 33-45, doi:10.5194/gmd-4-33-2011 (2011). Phipps, S. J. et al. Paleoclimate data-model comparison and the role of climate forcings over the past 1500 years. J. Clim., doi:10.1175/jcli-d-12-00108.1 (2013). Shapiro, A. I. et al. A new approach to the long-term reconstruction of the solar irradiance leads to large historical solar forcing. Astronomy and Astrophysics 529, A67, doi:10.1051/0004-6361/201016173 (2011). Schmidt, G. A. et al. Climate forcing reconstructions for use in PMIP simulations of the last millennium (v1.1). Geosci. Model Dev. 5, 185-191, doi:10.5194/gmd-5-185-2012 (2012). 

Variability over the Past Millennium. Part II: Reconstructions and Implications. J. Clim. 26, 2329-2352, doi:10.1175/jcli-d-11-00511.1 (2013).

27 Wang, G. J. \& Cai, W. J. Climate-change impact on the 20th-century relationship between the Southern Annular Mode and global mean temperature. Sci. Rep. 3, doi:2039. 10.1038/srep02039 (2013).

28 Barrand, N. E. et al. Trends in Antarctic Peninsula surface melting conditions from observations and regional climate modelling. J. Geophys. Res., doi:10.1029/2012JF002559 (2013).

29 Cai, W. et al. Increasing frequency of extreme El Nino events due to greenhouse warming. Nature Clim. Change 4, 111-116, doi:10.1038/nclimate2100 (2014).

30 Reynolds, R. W., Rayner, N. A., Smith, T. M., Stokes, D. C. \& Wang, W. An improved in situ and satellite SST analysis for climate. J. Clim. 15, 1609-1625 (2002). 
Table 1. Correlation statistics for the time series.

\begin{tabular}{|c|c|c|c|}
\hline Correlation series & $\begin{array}{l}\text { annual } \\
\text { averages }\end{array}$ & $\begin{array}{l}7 y \text { moving } \\
\text { averages }\end{array}$ & $\begin{array}{l}\text { 70y moving } \\
\text { averages }\end{array}$ \\
\hline $\begin{array}{l}\text { JRI temperature vs } \\
\text { Antarctic } 2 \mathrm{k} \text { temperature }\end{array}$ & $\begin{array}{l}r=-0.055^{*} \\
n=1006\end{array}$ & $r=-0.117^{*}$ & $r=-0.535 * * *$ \\
\hline $\begin{array}{l}\text { JRI temperature vs } \\
\text { South America2k temperature }\end{array}$ & $\begin{array}{l}r=0.008 \\
n=996\end{array}$ & $r=0.075$ & $r=0.247$ \\
\hline $\begin{array}{l}\text { SAM reconstruction vs } \\
\text { Niño3.4 reconstruction }\end{array}$ & $\begin{array}{l}r=-0.074^{* *} \\
\mathrm{n}=846\end{array}$ & $r=-0.163 * *$ & $r=-0.328^{*}$ \\
\hline $\begin{array}{l}\text { JRI temperature vs } \\
\text { Niño3.4 reconstruction }{ }^{26}\end{array}$ & $\begin{array}{l}r=-0.077^{* *} \\
\mathrm{n}=846\end{array}$ & $r=-0.189 * * *$ & $r=-0.379 *$ \\
\hline
\end{tabular}

Significance indicated as: ${ }^{*} p<0.1,{ }^{*} p<0.05$, and ${ }^{* *} p<0.01$, assessed using 1000 simulations of $A R(1)$ noise with the same length and lag-1 autocorrelation as the datasets. 


\section{Figure captions}

Figure 1. Regional temperature histories. a. JRI temperature reconstruction ${ }^{7,9}$ (green) alongside continent-scale temperature reconstructions ${ }^{5}$ for South America (red) and Antarctica (blue; excludes JRI). Anomalies shown as 7y (thin) and 70y (thick lines and grey shading) moving averages, relative to 1961-1990AD means (dashed). b, Location of JRI (green cross) and proxies used in the South America (red crosses) and Antarctica (blue crosses) temperature reconstructions. Shading shows spatial correlation $(p<0.1)$ of the annual SAM Index ${ }^{1}$ with $2 \mathrm{~m}$ air temperature in the ERA-Interim reanalysis ${ }^{16}$ (Jan-Dec averages; 1979-2012AD).

Figure 2. SAM reconstruction. a, Correlation of the proxy network to the annual (Jan-Dec) SAM Index ${ }^{1}$ during $^{1957-}$ 1995AD calibration interval. b, SAM reconstruction (grey line and shading) alongside Marshall ${ }^{1}$ (orange; 1957-2007AD) and Fogt ${ }^{10}$ (purple; 1905-2005AD) SAM Indices. All records shown at annual resolution (thin) and 7y moving averages (thick), relative to 1961-1990AD mean (dashed). c, SAM reconstruction for the last millennium, as 7y moving average (thin grey) and 70y loess filter (thick black), with 95\% confidence interval around the annual reconstruction (grey shading; with 70y loess smoothing), relative to 1961-1990AD mean (dashed black). Also shown are reduction of error $(R E)$ statistics (teal solid; which remain above $\mathrm{RE}_{\text {crit }}$ (dashed; $\left.\mathrm{p}=0.05\right)$ ), the number of contributing proxies, and $7 y$ moving averages of the Marshall (orange) and Fogt (purple) SAM Indices.

Figure 3. SAM data-model comparison. a, SAM reconstruction (black) compared with, b, a mid-latitude summer-SAM reconstruction ${ }^{18}$ (brown); both as 7y moving averages (thin) and 70y loess filter (thick). c, Ensemble mean (red) SAM Index across multi-model CMIP5 simulations ${ }^{21}$ (grey; 70y moving averages) using d, transient radiative forcing ${ }^{22}$ (example from CSIRO-Mk3L ${ }^{23}$, expressed relative to 1001-1200AD mean). SAM Indices (a-c) relative to 1961-1990AD means (dashed). e, CSIRO-Mk3L realisations of the SAM Index using progressive addition of radiative forcings ${ }^{23}$. Each curve represents the 3 ensemble average, as 70y moving averages relative to 1001-1200AD means (grey shading). Dashed lines show $\pm 2 \sigma$ range of internal variability based on orbital-only simulations.

Figure 4. ENSO teleconnections. a, Spatial correlation (Jan-Dec averages; 1982-2012AD; $p<0.1$ ) of Niño3.4 SST ${ }^{30}$ with $^{-1}$ ERA-Interim ${ }^{16} 2 m$ temperature demonstrating phasing of El Niño (La Niña) states with cooling (warming) in the Antarctic Peninsula region ${ }^{13}$. Black rectangle shows Niño3.4 region, black square shows JRI location. b, SAM reconstruction (black) and JRI temperature (green), shown alongside a multiproxy reconstruction ${ }^{26}$ of Niño3.4 SST (dark red). All shown as 7y moving averages (thin grey) and 70y loess filter (thick lines and grey shading), relative to 19611990AD means (dashed). 

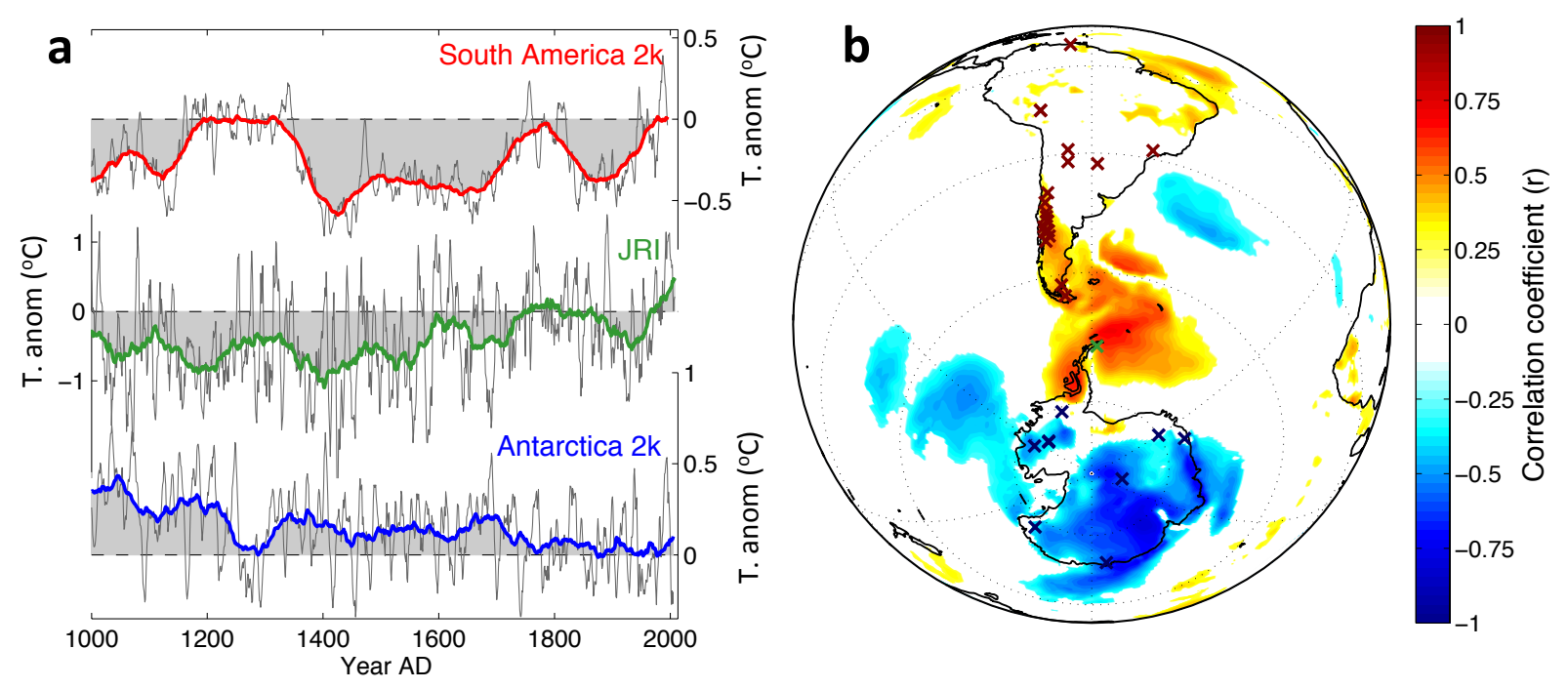

Figure 1. 

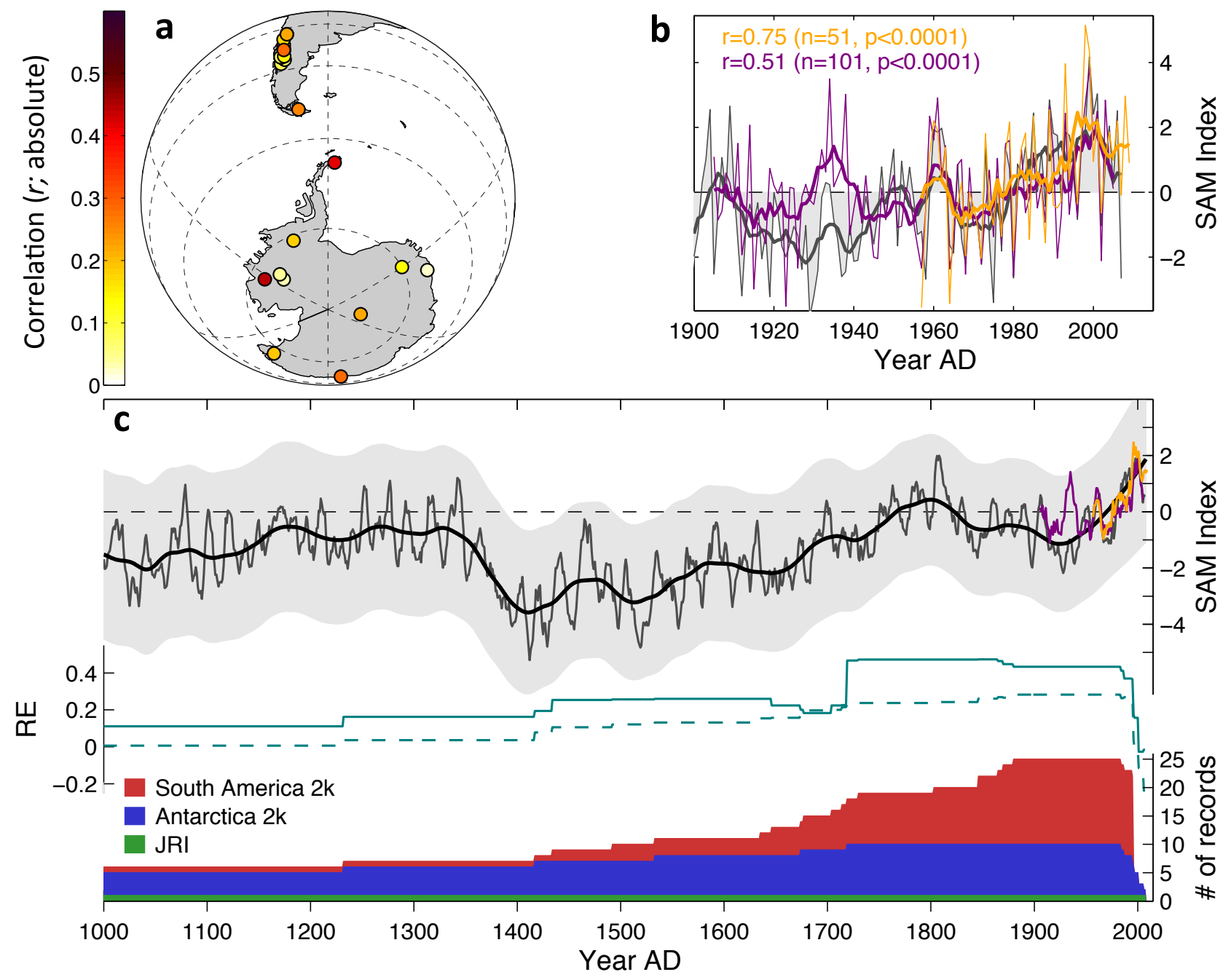

Figure 2. 

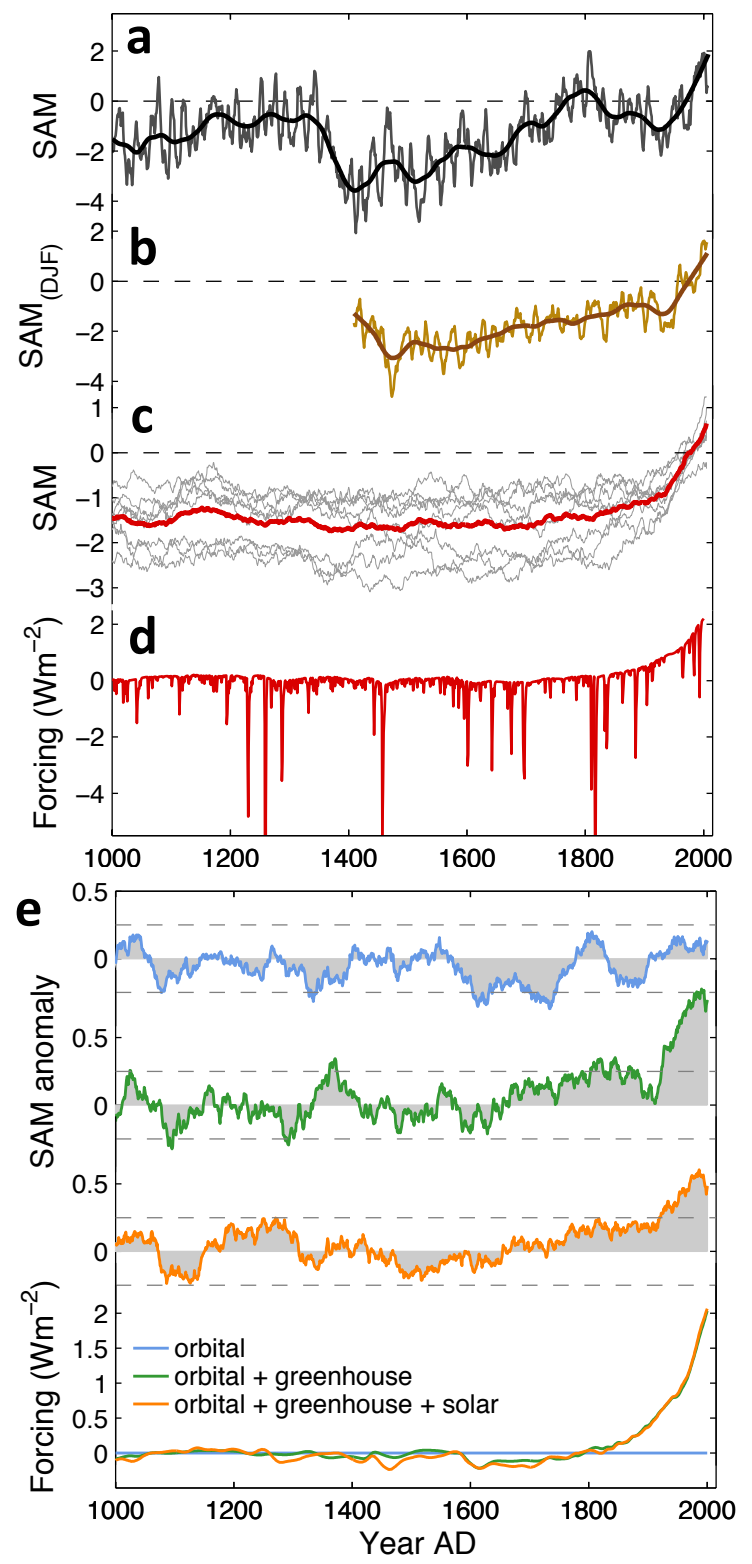

Figure 3. 

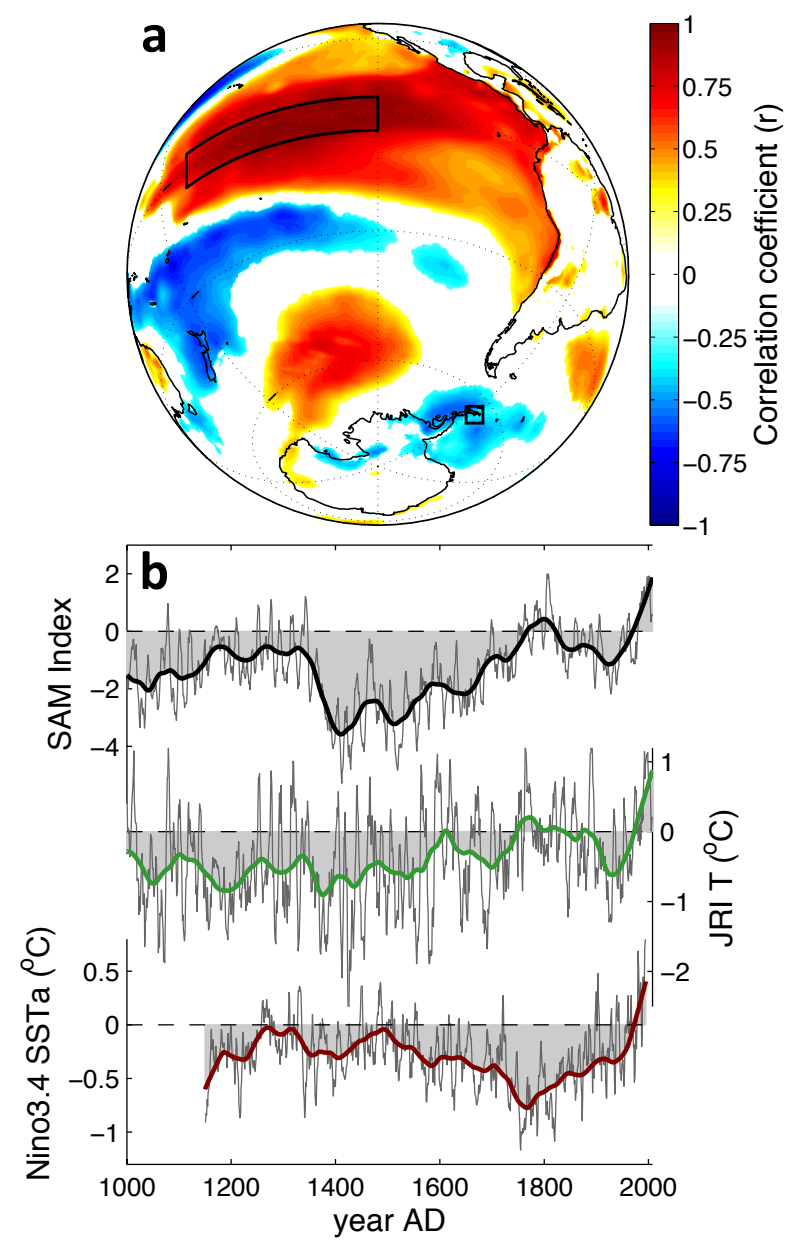

Figure 4. 


\section{Evolution of the Southern Annular Mode during the last millennium}

Nerilie J. Abram ${ }^{1,2}$, Robert Mulvaney ${ }^{1}$, Françoise Vimeux ${ }^{3}$, Steven J. Phipps ${ }^{4}$, John Turner $^{1}$ and Matthew H. England ${ }^{4}$

1. British Antarctic Survey, Natural Environment Research Council, Cambridge CB3 OET, United Kingdom

2. Research School of Earth Sciences, Australian National University, Canberra ACT 0200, Australia

3. Institut de Recherche pour le Développement, Laboratoire HydroSciences Montpellier et Laboratoire des Sciences du Climat et de l'Environment, 91191 Gif-sur-Yvette, France

4. Climate Change Research Centre and ARC Centre of Climate System Science, University of New South Wales, Sydney NSW 2052, Australia

\section{Contains:}

- Supplementary Table 1

- Supplementary Table 2

- Supplementary Figure 1

- Supplementary Figure 2

- Supplementary Figure 3

- Supplementary Figure 4

- Supplementary Figure 5

- Supplementary Figure 6

- Supplementary Figure 7

- Supplementary Figure 8

- Supplementary Figure 9

- Supplementary References 
Supplementary Table 1. Temperature-sensitive proxy records used for the SAM reconstruction.

\begin{tabular}{|c|c|c|c|c|c|c|c|c|c|}
\hline Region & Site & $\begin{array}{l}\text { Longitude } \\
\left({ }^{\circ} \mathrm{N}\right)\end{array}$ & $\begin{array}{c}\text { Latitude } \\
\left({ }^{\circ} \mathrm{E}\right)\end{array}$ & Proxy type & $\begin{array}{c}\text { Time coverage in } \\
\text { this study }\end{array}$ & Resolution & $\begin{array}{c}\text { Correlation }^{a} \\
\text { (r) }\end{array}$ & $\begin{array}{l}\text { Significance }^{a} \\
(p)\end{array}$ & References \\
\hline \multirow[t]{16}{*}{${ }^{*}$ South America ${ }^{b}$} & \multicolumn{3}{|c|}{ South America $2 \mathrm{k}$ temperature reconstruction } & & $1000-1996$ AD & annual & 0.207 & 0.187 & 1,2 \\
\hline & Laguna Aculeo & -33.14 & -70.15 & $\begin{array}{l}\text { Lake sediment } \\
\text { pigments }\end{array}$ & $1000-1996 \mathrm{AD}$ & $\begin{array}{c}\text { annual (3-5y } \\
\text { smoothed) }\end{array}$ & 0.225 & 0.179 & 3 \\
\hline & CAN composite 6 & -38.08 & -71.08 & Tree rings & $1434-1996 \mathrm{AD}$ & annual & 0.184 & 0.262 & $4-6$ \\
\hline & CAN composite 11 & -40.1 & -72.05 & Tree rings & $1492-1996 \mathrm{AD}$ & annual & -0.010 & 0.938 & 1 \\
\hline & Santa Lucia & -43 & -72.08 & Tree rings & $1646-1996 \mathrm{AD}$ & annual & 0.086 & 0.578 & 8 \\
\hline & CAN composite 9 & -39.06 & -71.04 & Tree rings & $1635-1996$ AD & annual & -0.002 & 0.988 & 4,5 \\
\hline & CAN composite 24 & -42.08 & -71.06 & Tree rings & $1677-1996 \mathrm{AD}$ & annual & -0.079 & 0.655 & 4,1 \\
\hline & CAN composite 4 & -39 & -71.08 & Tree rings & $1704-1996$ AD & annual & -0.289 & $0.090^{*}$ & 9,10 \\
\hline & CAN composite 2 & -37.14 & -71 & Tree rings & $1714-1996 \mathrm{AD}$ & annual & 0.056 & 0.717 & 4,5 \\
\hline & CAN composite 31 & -39.03 & -71.05 & Tree rings & $1730-1996$ AD & annual & 0.179 & 0.252 & 5 \\
\hline & Glaciar Frias & -41.2 & -71.9 & Tree rings & $1803-1996$ AD & annual & -0.012 & 0.942 & 11 \\
\hline & SAN composite 2 & -54.2 & -68.7 & Tree rings & $1846-1996$ AD & annual & -0.259 & $0.090^{\star}$ & 12 \\
\hline & CAN composite 16 & -41.02 & -71.13 & Tree rings & $1846-1996$ AD & annual & -0.052 & 0.702 & 13 \\
\hline & CAN composite 19 & -41.03 & -72.04 & Tree rings & $1865-1996$ AD & annual & 0.072 & 0.661 & 14 \\
\hline & CAN composite 14 & -41.02 & -71.13 & Tree rings & $1870-1996$ AD & annual & 0.146 & 0.307 & 10,13 \\
\hline & Vilches & -35.1 & -71.01 & Tree rings & $1880-1996$ AD & annual & -0.170 & 0.345 & 9 \\
\hline Antarctic Peninsula & James Ross Island & -64.20 & -57.69 & Ice core $\delta \mathrm{D}$ & $1000-2008$ AD & annual & 0.418 & $0.015^{* *}$ & $\mid 15-11$ \\
\hline \multirow[t]{10}{*}{ Antarctica } & \multicolumn{3}{|c|}{ Antarctica $2 \mathrm{k}$ temperature reconstruction } & & $1000-2005 \mathrm{AD}$ & annual & -0.089 & 0.639 & 1 \\
\hline & Talos Dome & -72.48 & 159.06 & Ice core $\delta D$ & $1232-1996 \mathrm{AD}$ & annual & -0.194 & 0.252 & 18,19 \\
\hline & Law Dome DSS & -66.77 & 112.81 & Ice core $\delta^{18} \mathrm{O}$ & $1000-2008 \mathrm{AD}$ & annual & -0.282 & $0.090^{*}$ & 20 \\
\hline & Plateau Remote & -84 & 43 & Ice core $\delta^{18} \mathrm{O}$ & $1000-1987 \mathrm{AD}$ & annual & $\begin{array}{c}-0.202 \\
0.219\end{array}$ & 0.246 & 21,22 \\
\hline & IND-22 B4 & -70.86 & 11.54 & Ice core $\delta^{18} \mathrm{O}$ & $1533-1995 A D$ & annual & -0.026 & 0.876 & 23,24 \\
\hline & $\mathrm{EDML}$ & -75 & 0 & Ice core $\delta^{18} \mathrm{O}$ & $1000-1997 \mathrm{AD}$ & annual & 0.139 & 0.419 & 25 \\
\hline & WAIS composite & -79.46 & -112.09 & Ice core $\delta^{18} \mathrm{O}$ & $1000-2006 \mathrm{AD}$ & annual & 0.032 & 0.836 & 26,21 \\
\hline & ITASE 00-1 & $\begin{array}{l}-15.40 \\
-79.38\end{array}$ & -111.24 & Ice core $\delta^{18} \mathrm{O}$ & $1674-2001 A D$ & annual & $\begin{array}{l}0.032 \\
0.045\end{array}$ & 0.001 & 28 \\
\hline & ITASE 00-5 & -77.68 & -124.00 & Ice core $\delta D$ & $1719-2001 A D$ & annual & -0.441 & $0.021^{\star *}$ & 28 \\
\hline & Siple Station & -75.92 & -84.25 & Ice core $\delta^{18} \mathrm{O}$ & $1417-1984 A D$ & annual & 0.187 & 0.350 & 28,29 \\
\hline \multirow{4}{*}{$\begin{array}{l}\text { SAM } \\
\text { Reconstructions }\end{array}$} & \multicolumn{4}{|c|}{ Weighted CPS (individual proxies; weighted by r-value) } & $1000-2008$ AD & annual & 0.750 & $<0.001^{* * *}$ & This study \\
\hline & \multicolumn{4}{|c|}{ Unweighted CPS (individual proxies) } & $1000-2008$ AD & annual & 0.671 & $<0.001^{\star \star *}$ & This study \\
\hline & \multicolumn{4}{|c|}{ Screened CPS (subset of individual proxies; $p<0.1$ ) } & $1000-2008 \mathrm{AD}$ & annual & 0.679 & $<0.001^{* * *}$ & This study \\
\hline & \multicolumn{4}{|c|}{ Weighted CPS (regional reconstructions) } & $1000-2008$ AD & annual & 0.558 & $<0.001^{* * *}$ & This study \\
\hline
\end{tabular}

${ }^{a}$ Statistics are for correlation of proxies with annual (Jan-Dec) Marshall SAM Index ${ }^{30}$ during the 1957-1995 calibration interval. The r-values are derived from the

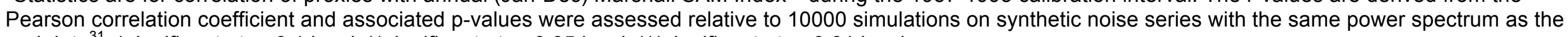
real data ${ }^{31}$ : *significant at $p<0.1$ level, ** significant at $p<0.05$ level, ${ }^{* * *}$ significant at $p<0.01$ level.

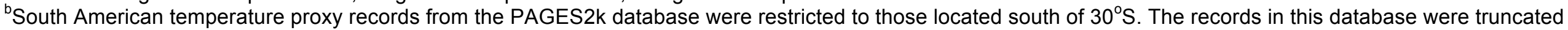
after 1995AD. Tree-ring proxies may contain climate information from spring growth in the year prior to the Jan-Dec calendar year used in this study. 
Supplementary Table 2. Details of the last millennium (past1000) and historical data files from the CMIP5 simulations used in this study. Data files refer to model simulation data that was accessed from the Earth System Grid Federation node (http://pcmdi9.IInl.gov/esgf-web-fe/). Mean sea level pressure data were used to construct the SAM Index, and surface air temperature data were used to test the regional temperature patterns associated with SAM variability. Note that the number of models that have run the transient last millennium experiment is smaller than the full set of CMIP5 climate models.

\begin{tabular}{|c|c|c|c|c|c|}
\hline \multirow[t]{2}{*}{ Model } & \multicolumn{2}{|c|}{ Mean sea level pressure (psl) data files } & \multicolumn{2}{|c|}{ Surface air temperature (tas) data files } & \multirow[t]{2}{*}{ References } \\
\hline & Past1000 & Historical & Past1000 & Historical & \\
\hline BCC-CSM1.1 & $\begin{array}{l}\text { psl_Amon_bcc-csm1- } \\
\text { 1_past1000_r1i1p1_085001- } \\
\text { 185012.nc }\end{array}$ & $\begin{array}{l}\text { psl_Amon_bcc-csm1- } \\
\text { 1_past1000_r1i1p1_185101- } \\
\text { 200012.nc }\end{array}$ & $\begin{array}{l}\text { tas_Amon_bcc-csm1- } \\
\text { 1_past1000_r1i1p1_085001- } \\
\text { 185012.nc }\end{array}$ & $\begin{array}{l}\text { tas_Amon_bcc-csm1- } \\
\text { 1_past1000_r1i1p1_185101- } \\
\text { 200012.nc }\end{array}$ & $\begin{array}{l}\text { http://bcc.cma.gov.cn/bcccsm/web/chan } \\
\text { nel-34.htm }\end{array}$ \\
\hline MIROC-ESM & $\begin{array}{l}\text { psl_Amon_MIROC- } \\
\text { ESM_past1000_r1i1p1_08500 } \\
\text { 1-184912.nc }\end{array}$ & $\begin{array}{l}\text { psl_Amon_MIROC- } \\
\text { ESM_historical_r1i1p1_18500 } \\
\text { 1-200512.nc }\end{array}$ & $\begin{array}{l}\text { tas_Amon_MIROC- } \\
\text { ESM_past1000_r1i1p1_08500 } \\
\text { 1-184912.nc }\end{array}$ & $\begin{array}{l}\text { tas_Amon_MIROC- } \\
\text { ESM_historical_r1i1p1_18500 } \\
\text { 1-200512.nc }\end{array}$ & 32 \\
\hline IPSL CM5A-LR & $\begin{array}{l}\text { psl_Amon_IPSL-CM5A- } \\
\text { LR_past1000_r1i1p1_085001- } \\
\text { 104912.nc to } \\
\text { psl_Amon_IPSL-CM5A- } \\
\text { LR_past1000_r1i1p1_185001- } \\
\text { 185012.nc }\end{array}$ & $\begin{array}{l}\text { psl_Amon_IPSL-CM5A- } \\
\text { LR_historical_r1i1p1_185001- } \\
\text { 200512.nc }\end{array}$ & $\begin{array}{l}\text { tas_Amon_IPSL-CM5A- } \\
\text { LR_past1000_r1i1p1_085001- } \\
\text { 104912.nc to } \\
\text { tas_Amon_IPSL-CM5A- } \\
\text { LR_past1000_r1i1p1_185001- } \\
\text { 185012.nc }\end{array}$ & $\begin{array}{l}\text { tas_Amon_IPSL-CM5A- } \\
\text { LR_historical_r1i1p1_185001- } \\
\text { 200512.nc }\end{array}$ & http://icmc.ipsl.fr/index.php/cmip5 \\
\hline MPI-ESM-P & $\begin{array}{l}\text { psl_Amon_MPI-ESM- } \\
\text { P_past1000_r1i1p1_085001- } \\
\text { 184912.nc }\end{array}$ & $\begin{array}{l}\text { psl_Amon_MPI-ESM- } \\
\text { P_historical_r1i1p1_185001- } \\
\text { 200512.nc }\end{array}$ & $\begin{array}{l}\text { tas_Amon_MPI-ESM- } \\
\text { P_past1000_r1i1p1_085001- } \\
\text { 184912.nc }\end{array}$ & $\begin{array}{l}\text { tas_Amon_MPI-ESM- } \\
\text { P_historical_r1i1p1_185001- } \\
\text { 200512.nc }\end{array}$ & $\begin{array}{l}33 \\
\text { http://www.mpimet.mpg.de/en/science/m } \\
\text { odels/mpi-esm.html }\end{array}$ \\
\hline NCAR CCSM4 & $\begin{array}{l}\text { psl_Amon_CCSM4_past1000 } \\
\text { r1i1p1_085001-185012.nc }\end{array}$ & $\begin{array}{l}\text { psl_Amon_CCSM4_historical_ } \\
\text { r1i1p1_185001-200512.nc }\end{array}$ & $\begin{array}{l}\text { tas_Amon_CCSM4_past1000 } \\
\text { r111p1_085001-185012.nc }\end{array}$ & $\begin{array}{l}\text { tas_Amon_CCSM4_historical_ } \\
\text { r1i1p1_185001-200512.nc }\end{array}$ & http //www.cesm ucar edu/experiments/ \\
\hline HadCM3 & $\begin{array}{l}\text { psl_Amon_HadCM3_past1000 } \\
\text { r1i1p1_085001-185012.nc }\end{array}$ & pers. comm. & $\begin{array}{l}\text { tas_Amon_HadCM3_past1000 } \\
\text { r1i1p1_085001-185012.nc }\end{array}$ & pers. comm & 35 \\
\hline GISS-E2-R & $\begin{array}{l}\text { psl_Amon_GISS-E2- } \\
\text { R_past1000_r1i1p124_08500 } \\
\text { 1-089912.nc to } \\
\text { psl_Amon_GISS-E2- } \\
\text { R_past1000_r1i1p124_18010 } \\
\text { 1-185012.nc }\end{array}$ & $\begin{array}{l}\text { psl_Amon_GISS-E2- } \\
\text { R_historical_r1i1p124_185101 } \\
\text {-187512.nc to } \\
\text { psl_Amon_GISS-E2- } \\
\text { R_historical_r1i1p124_200101 } \\
\text {-200512.nc }\end{array}$ & $\begin{array}{l}\text { tas_Amon_GISS-E2- } \\
\text { R_past1000_r1i1p124_08500 } \\
\text { 1-089912.nc to } \\
\text { tas_Amon_GISS-E2- } \\
\text { R_past1000_r1i1p124_18010 } \\
\text { 1-185012.nc }\end{array}$ & $\begin{array}{l}\text { tas_Amon_GISS-E2- } \\
\text { R_historical_r1i1p124_185101 } \\
\text {-187512.nc to } \\
\text { tas_Amon_GISS-E2- } \\
\text { R_historical_r111p124_200101 } \\
\text {-200512.nc }\end{array}$ & http://data.giss.nasa.gov/modelE/ar5/ \\
\hline CSIRO-Mk3L v1.2 & \multicolumn{2}{|l|}{ Orbital (3 ensemble members) } & & & 36 \\
\hline CSIRO-Mk3L v1.2 & \multicolumn{2}{|c|}{ Orbital + Greenhouse (3 ensemble members) } & & & 36 \\
\hline CSIRO-Mk3L v1.2 & \multicolumn{2}{|c|}{ Orbital + Greenhouse + Solar (3 ensemble members) } & & & 36 \\
\hline CSIRO-Mk3L v1.2 & \multicolumn{2}{|c|}{ Orbital + Greenhouse + Solar + Volcanic (3 ensemble members) } & \multicolumn{2}{|c|}{ Orbital + Greenhouse + Solar + Volcanic $\left(1^{\text {st }}\right.$ ensemble member $)$} & 36 \\
\hline
\end{tabular}




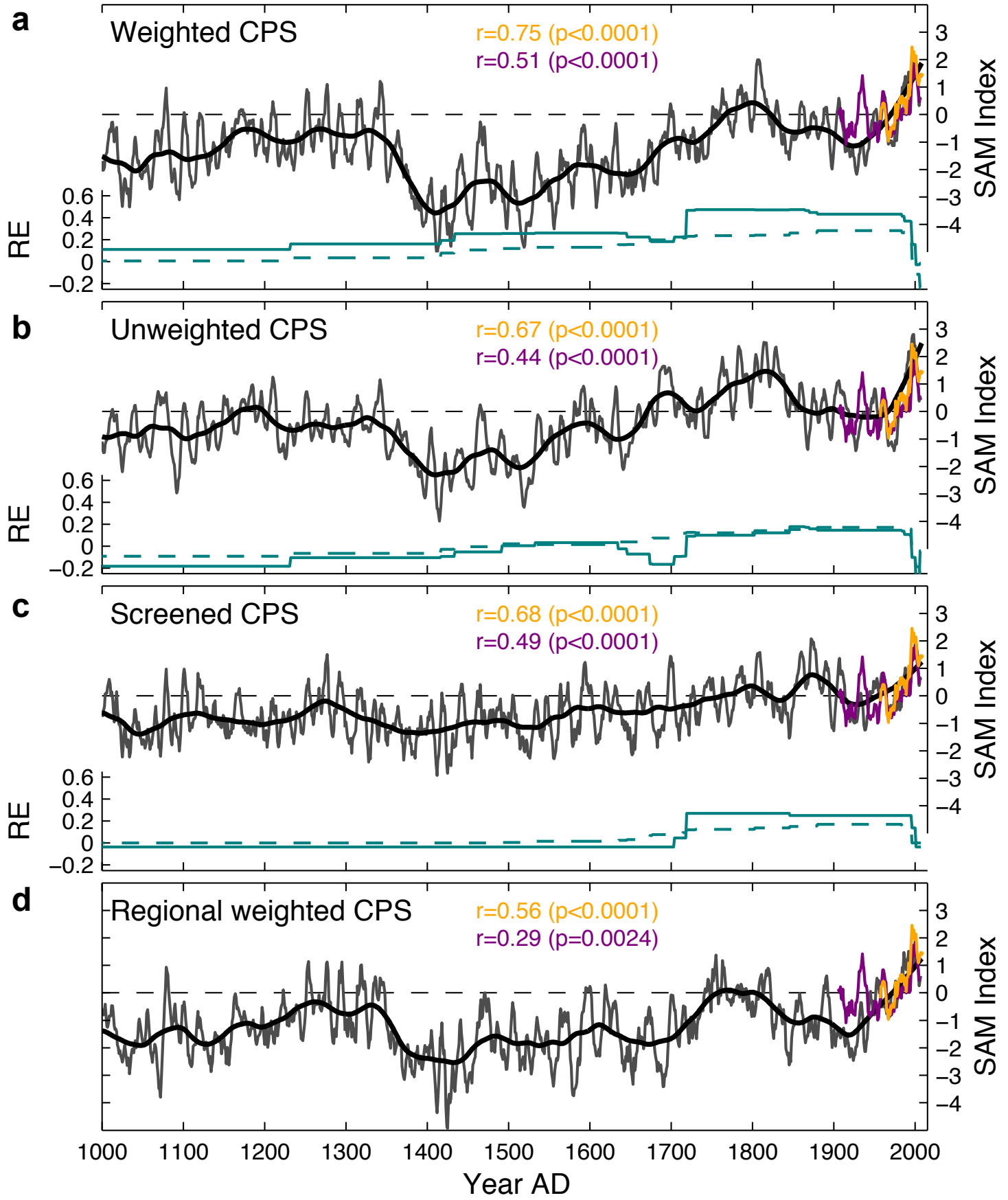

Supplementary Figure 1. Comparison of SAM reconstructions produced using different composite-plus-scale (CPS) methods. SAM reconstructions for the last millennium (grey: 7y moving averages, black: 70y loess filter) shown relative to 1961-1990 mean (black dashed), with nested reduction of error (RE; teal solid) statistics and upper 95\% RE values ( $R E_{\text {crit; }}$ teal dashed) based on $1000 \mathrm{AR}(1)$ time series with the same length and lag-1 autocorrelation as the proxy network. Also shown are 7y moving averages of, and annual correlation statistics with, the Marshall (orange; $n=51 ; 1957-2007$ ) and Fogt (purple; $n=101 ; 1905-2005$ ) SAM indices. All SAM Indices are based on January-December annual averages, except the Fogt Index which is based on December-November annuals.

a, SAM reconstruction compiled using a weighted combination of the individual proxy records based on each record's correlation coefficient $(r)$ with the Marshall-SAM Index during the 1957-1995 calibration interval (Supplementary Table 1). The weighted CPS reconstruction produces the highest correlation statistics of each of the methods compared here, and throughout its length $R E$ remains above $R E_{\text {crit }}(p<0.05)$.

b, SAM reconstruction using an unweighted CPS compilation of the individual proxy records. In this method the main features of the weighted-CPS SAM reconstruction are retained, as is a significant correlation 
with instrumental SAM records, but the reduction of error statistics fall slightly below the upper $95^{\text {th }}$ percentile of 1000 unweighted CPS reconstructions using red noise series. The reduction in skill for the unweighted SAM reconstruction is expected because although there is an a priori expectation that the proxies we use have some sensitivity to SAM-related temperature variability, many of the individual proxies do not display a strong relationship with the instrumental SAM Index (Supplementary Table 1).

c, SAM reconstruction using an unweighted CPS compilation of a screened subset of the proxy records that display a significant $(p<0.1)$ correlation with the Marshall SAM-Index during the calibration interval (Supplementary Table 1). The screening method greatly reduces the number of proxies that contribute to the SAM reconstruction $(n=5)$. The main trends of SAM strengthening since the $15^{\text {th }}$ century are retained in this reconstruction, but with a reduced magnitude of long-term change. The trend in the screened-CPS SAM Index since 1940AD is +0.2 units/decade (c.f. +0.3 units/decade for the weighted-CPS SAM Index; main text). The mean trend in the screened-CPS SAM Index during the $16^{\text {th }}-18^{\text {th }}$ centuries $(1501-1800 A D)$ is +0.04 units/decade (c.f. +0.1 units/decade for the weighted-CPS SAM Index; main text).

d, SAM reconstruction where the weighted CPS reconstruction was performed using the three regional temperature reconstructions provided by the PAGES South America $2 \mathrm{k}$ reconstruction, the PAGES Antarctica $2 \mathrm{k}$ reconstruction and the James Ross Island ice core (Antarctic Peninsula) (Supplementary Table 1). This method is similar to that used by Villalba et al., (ref. ${ }^{37}$ ), where three regional-scale reconstructions from mid-latitude tree rings were combined (using principle component analysis) to reconstruction the summer SAM Index. Our weighted regional SAM reconstruction has lower, but still highly significant, correlation statistics with instrumental SAM records and shows a very similar pattern of long-term SAM evolution to the reconstructions based on individual proxy records. 


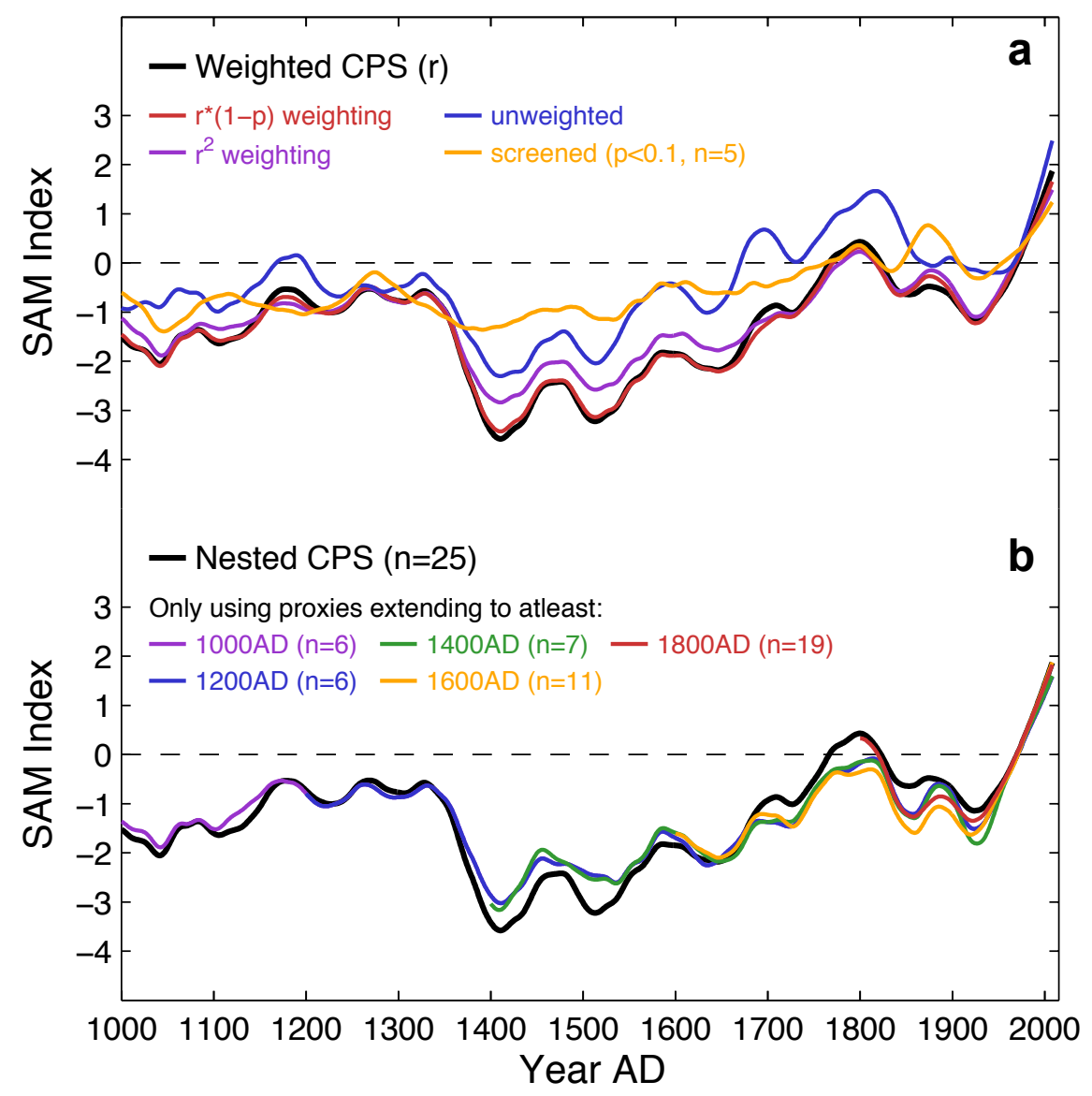

Supplementary Figure 2. Comparison of SAM reconstructions produced using different a, weighting and b, nesting methods. Curves show a 70-year loess filter of the various SAM reconstructions.

a. Comparison of different CPS weighting methods. Weighting of individual records in CPS compilations is commonly based on a physical measure of each record's suitability at representing the target being reconstructed ${ }^{38}$, however there is no accepted best-practice method for determining this measure. In this study we follow the method of Hegerl et al., $\left(\right.$ ref $^{39}$ ) and weight the contribution of each record to the CPS reconstruction based on its correlation coefficient $(r)$ with the Marshall-SAM Index during the 1957-1995 calibration interval (black; Supplementary Table 1; Supplementary Figure 1a). Similar long-term changes in the SAM Index are also produced by weighting each proxy based on its correlation to the Marshall-SAM Index and the significance of that relationship taking into account autocorrelation, using the formula $r \times(1-p)$ (red). Weighting the individual records based on the proportion of their variance $\left(r^{2}\right.$; purple) that is explained by SAM during the 1957-1995 calibration interval also does not alter any of the results discussed in this paper. For comparison the 70-year loess filters are also shown for the SAM reconstructions using no weighting (blue; Supplementary Figure 1b) and using a screened subset of proxies (orange; Supplementary Figure 1c).

b. Comparison of the CPS nesting procedure. The SAM reconstruction (black) is produced using an iterative nesting procedure to take into account the variable length of contributing proxies. For comparison we also produce weighted CPS reconstructions without nesting that are based only on the proxies that extend continuously back to at least $1800 \mathrm{AD}$ (red), $1600 \mathrm{AD}$ (orange), $1400 \mathrm{AD}$ (green), $1200 \mathrm{AD}$ (blue) and 1000 $A D$ (purple). Note that the $1200 A D$ and $1000 A D$ reconstructions are based on the same subset of proxies. There are no substantial differences between the SAM reconstructions produced with or without nesting of the proxies. 


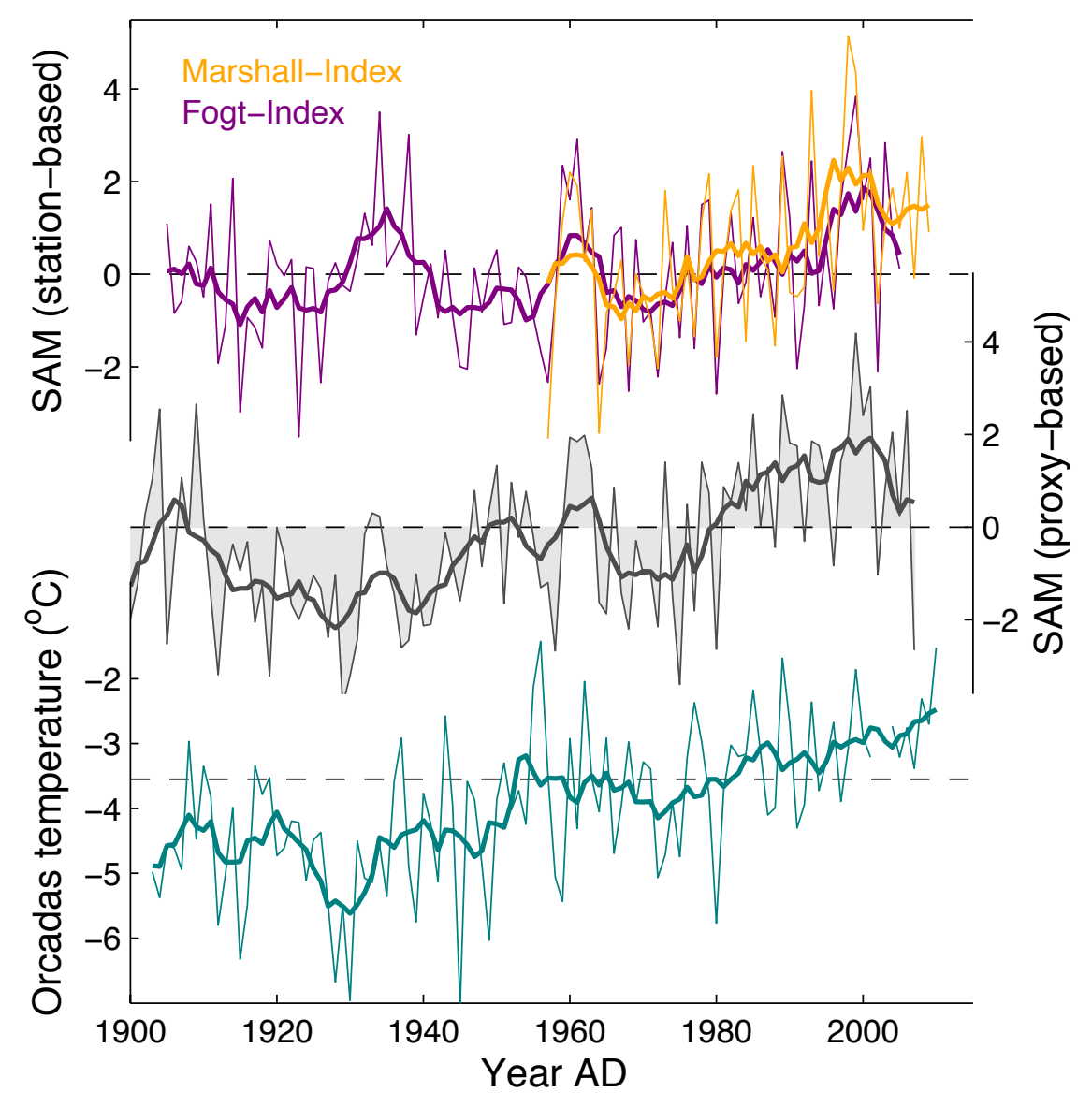

Supplementary Figure 3. Comparison of SAM Indices during the $20^{\text {th }}$ Century. The Marshall (orange) ${ }^{30}$ and Fogt $^{40,41}$ (purple) SAM Indices based on station observations of mean sea level pressure, with the proxybased SAM reconstruction (grey), and an observational record of temperature (teal) at Orcadas station on the South Orkney Islands $\left(60^{\circ} 44^{\prime} \mathrm{S}, 44^{\circ} 45^{\prime} \mathrm{W}\right.$; data available http://www.antarctica.ac.uk/met/READER/). All records shown as annual averages (thin) and 7y moving averages (thick) relative to 1961-1990 mean (dashed). All records are based on January-December annual averages, except the Fogt Index which is based on December-November annuals.

The proxy-based SAM reconstruction (grey) has a significant correlation with the extended Fogt SAM Index (purple) (Supplementary Table 1), but a notable difference in mean SAM values occurs during the 1930s when the station-based reconstruction indicates a more positive mean SAM state. Jones et al. ${ }^{41}$ note that the prominent SAM anomaly in the Fogt-SAM Index during the 1930s is more positive than suggested by the HadSLP2 dataset. A possible explanation for the difference in the extended station-based SAM reconstruction and our proxy-based reconstruction could lie in the reconstruction methods. The extended Fogt-SAM index was reconstructed by fitting a model based on the detrended relationship between SAM and station observations of mean sea level pressure ${ }^{41}$. Other climate reconstruction studies have shown that linear detrending hinders the ability to reconstruct long-term trends ${ }^{42}$ and because of this we do not use detrended records for the proxy-based SAM reconstruction.

Another possibility for the proxy-station differences in derived SAM records during the 1930s could be that the proxy network includes Antarctic climate information whereas the extended Fogt-SAM Index is derived almost entirely from mid-latitude station data due to the sparcity of Antarctic observations prior to 1957. The exception is the Orcadas station data which begins in 1903, however mean sea level pressure at Orcadas is poorly correlated with SAM ( $r=-0.192, p=0.176, n=51$ annual averages) because the station lies between the Antarctic and mid-latitude regions of opposing SAM-related pressure anomalies (Supplementary Figure 5a). However, Orcadas does lie within the westerly wind belt and temperature at the site is highly correlated $(r=0.417, p=0.0024)$ with SAM (Fig. 1 , Supplementary Figure $5 b)$. The Orcadas temperature record shows a cool anomaly during the 1930s that is consistent with the more negative SAM values that we obtain through the proxy-based reconstruction. 


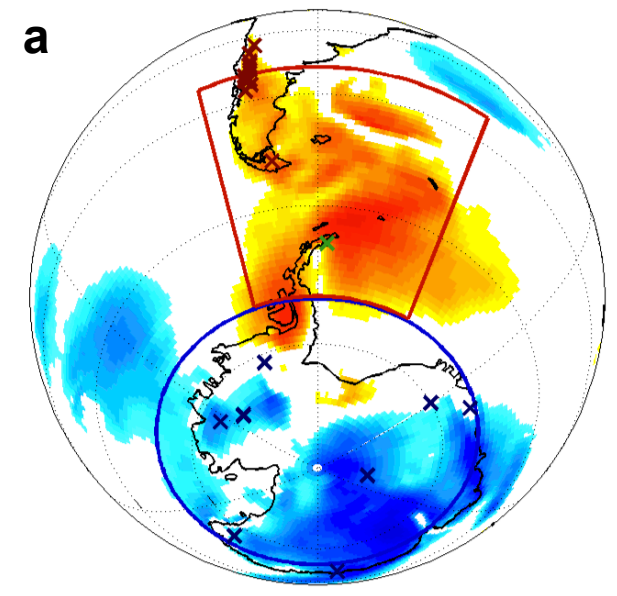

\begin{tabular}{|c|c|c|}
\hline Model & $\begin{array}{l}\text { South America and } \\
\text { Antarctic Peninsula } \\
\left(40-70^{\circ} \mathrm{S}, 80-30^{\circ} \mathrm{W}\right)\end{array}$ & $\begin{array}{l}\text { Antarctic continent } \\
\left(70-90^{\circ} \mathrm{S}, 180^{\circ} \mathrm{E}-180^{\circ} \mathrm{W}\right)\end{array}$ \\
\hline $\mathrm{BCC}$ & $r=0.123, p<0.001$ & $r=-0.397, p<0.001$ \\
\hline CCSM4 & $r=0.460, p<0.001$ & $r=-0.153, p<0.001$ \\
\hline HadCM3 & $r=0.265, p<0.001$ & $r=-0.535, p<0.001$ \\
\hline IPSL & $r=0.117, p<0.001$ & $r=-0.577, p<0.001$ \\
\hline MIROC & $r=0.099, p=0.002$ & $r=-0.042, p=0.188$ \\
\hline $\mathrm{MPI}$ & $r=0.205, p<0.001$ & $r=-0.464, p<0.001$ \\
\hline GISS & $r=0.066, p=0.009$ & $r=-0.307, p<0.001$ \\
\hline CSIRO & $r=0.241, p<0.001$ & $r=-0.536, p<0.001$ \\
\hline
\end{tabular}

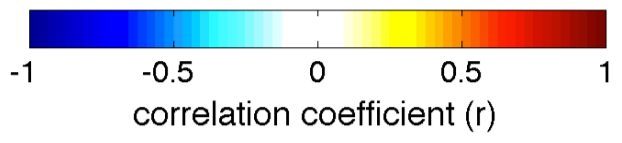

C
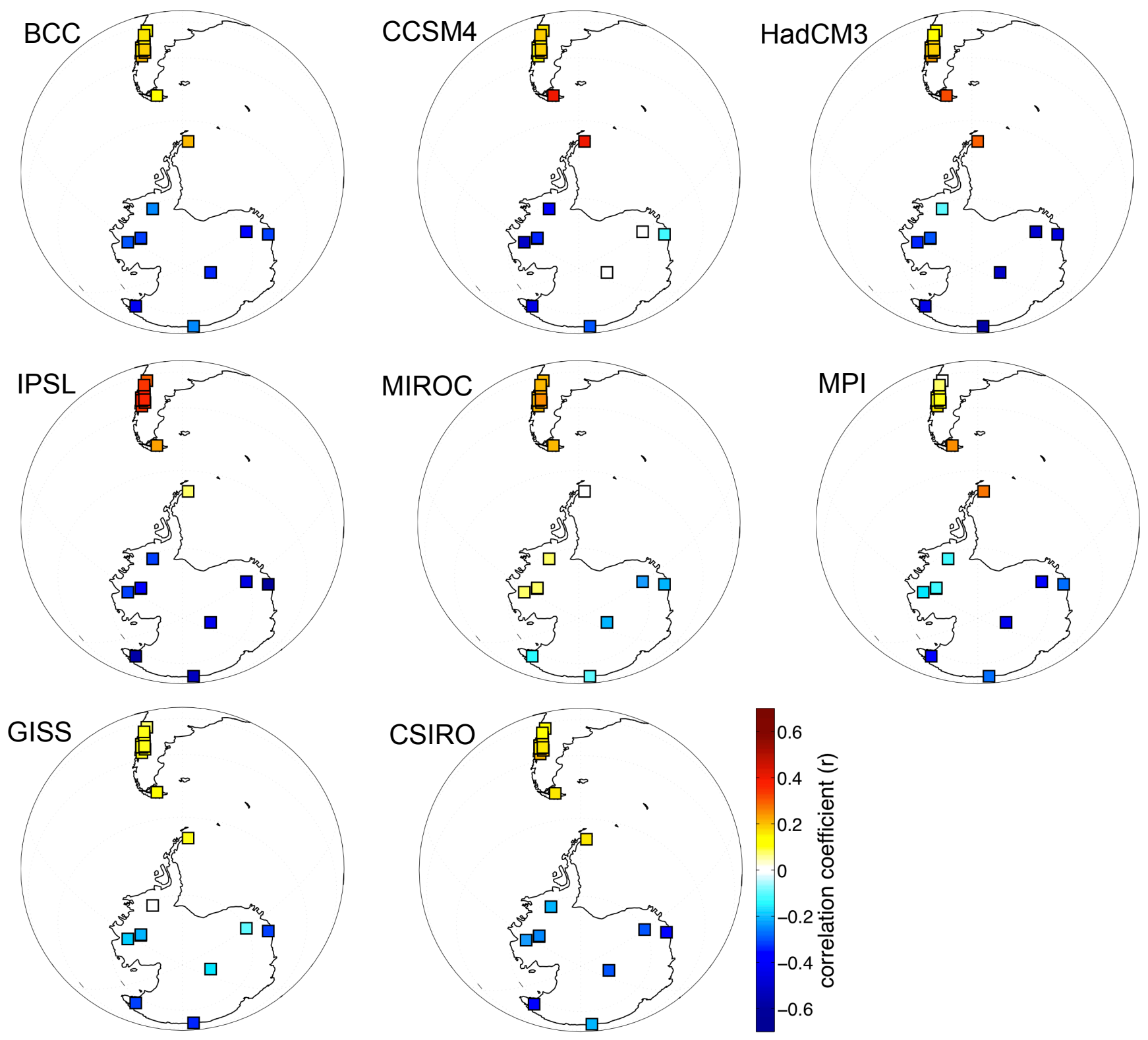

Supplementary Figure 4. SAM-temperature relationships in CMIP5 last millennium simulations. 
a, The spatial correlation of annual (Jan-Dec) ERA-Interim $2 \mathrm{~m}$ air temperature with the Marshall-SAM Index since 1979. Shading denotes correlations that are significant above the $p=0.1$ level and crosses denote the location of the proxy records used in this study (as in Fig. 1b). Red box shows the South America and Antarctic Peninsula $\left(40-70^{\circ} \mathrm{S}, 80-30^{\circ} \mathrm{W}\right)$ region and blue circle shows the Antarctic continent $\left(70-90^{\circ} \mathrm{S}, 180^{\circ} \mathrm{E}-\right.$ $180^{\circ} \mathrm{W}$ ) region used in $\mathrm{b}$, table showing the correlation of SAM in CMIP5 last millennium climate simulations with regionally averaged surface air temperature over the South America/Antarctic Peninsula and Antarctic continent regions in the same models. Correlations are based on annual average SAM and surface air temperature values since 1000AD. C. Spatial maps of the correlation of annual average surface air temperature with SAM since 1000AD in the CMIP5 last millennium simulations, where surface air temperature has been sampled at grid boxes corresponding to the proxy network used in this study. Only correlations exceeding the $p=0.1$ level are shaded.

The regional responses of temperature to the SAM in the last millennium simulations (b and c) retain a spatial pattern that matches the observed relationship in ERA-Interim reanalysis data since 1979 (a); such that positive SAM phases correspond with warming over South America and the Antarctic Peninsula and cooling over the Antarctic continent. A previous study has noted non-stationarity in SAM-temperature relationships at sites in Dronning Maud Land ${ }^{43}$, peripheral to the regions of significant SAM-related temperature variability. However the consistency of modeled SAM-temperature relationships since 1000AD with modern observations suggests that the regional-scale interannual response of temperature to the SAM is a persistent climate feature in the Drake Passage sector. 

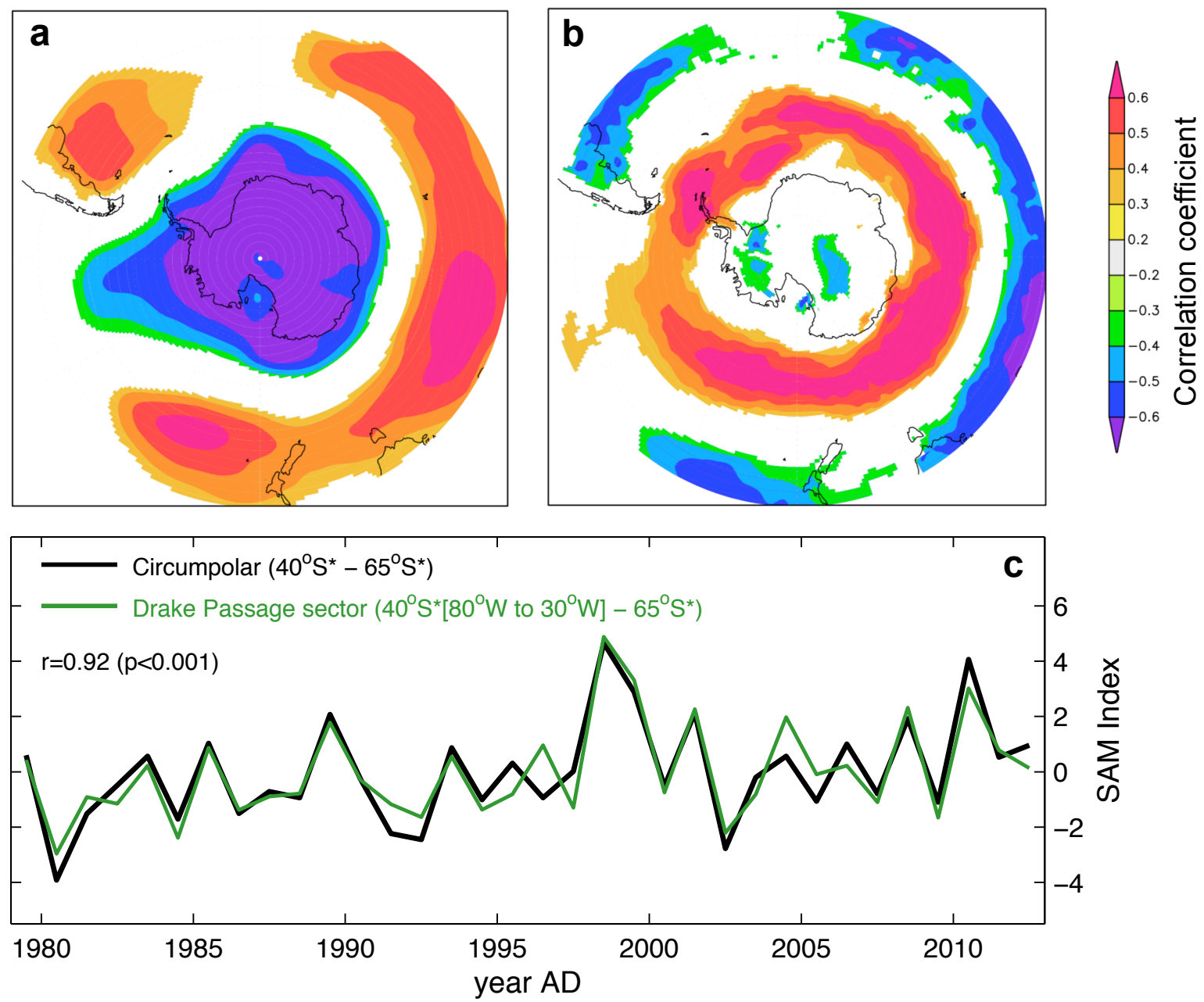

Supplementary Figure 5. Comparison of SAM across the Drake Passage sector with the circumpolar expression of SAM using ERA-Interim reanalysis data. Spatial correlation of our SAM reconstruction with a, mean sea level pressure and $b$, surface zonal wind fields from the ERA-Interim ${ }^{44}$ reanalysis. Correlations are for January-December annual averages from 1979-2007, and only correlations that are significant above the $p$ $=0.1$ level are shaded. c, Time series of the annual (Jan-Dec) SAM Index since 1979 produced using ERAInterim mean sea level pressure fields incorporating mid-latitude $\left(40^{\circ} \mathrm{S}\right)$ data from the full circum-polar region $\left(180^{\circ} \mathrm{W}-180^{\circ} \mathrm{E}\right.$; black) and restricted to the Drake Passage sector $\left(80^{\circ} \mathrm{W}-30^{\circ} \mathrm{W}\right.$; green).

The SAM reconstruction produced in this study using polar to mid-latitude proxies across the Drake Passage sector (Fig. 2, Supplementary Table 1) produces a spatial correlation pattern that resembles a SAM pattern around the full circum-polar domain ( $a$ and $b$ ). ERA Interim reanalysis data also demonstrates that the SAM Index produced using mid-latitude data restricted to the South America region is highly correlated with the SAM Index derived using the full circumpolar pressure field (c). Together these comparisons demonstrate the ability for the Drake Passage sector SAM reconstruction to represent SAM in the full circumpolar domain. CMIP5 models also verify this over the last millennium (Supplementary Figure 6). 


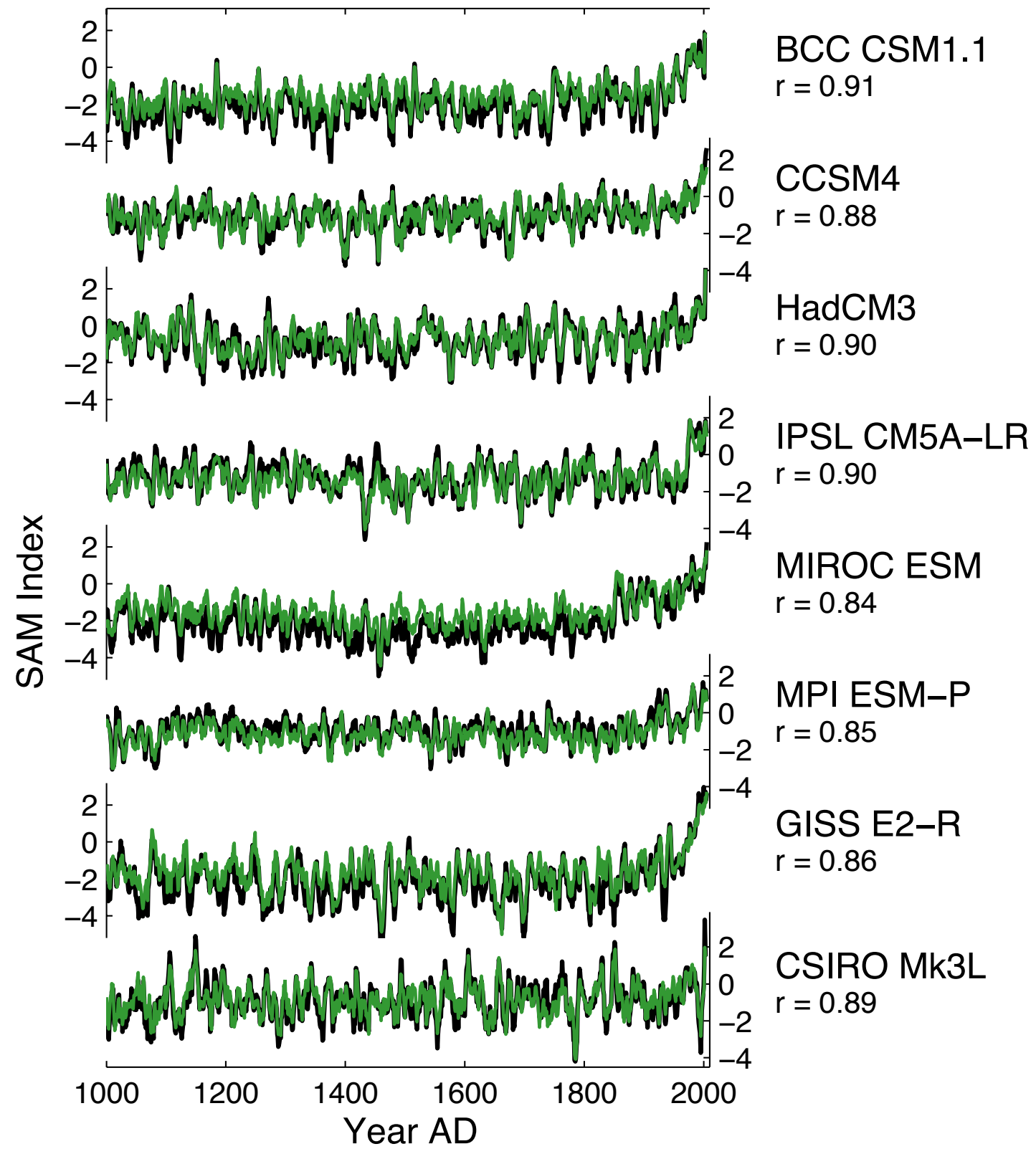

Supplementary Figure 6. Comparison of SAM across the Drake Passage sector with the circumpolar expression of SAM in CMIP5 last millennium climate simulations. Time series show 7-year moving averages of the annual (Jan-Dec) SAM Index since 1000AD produced using model mean sea level pressure data. In all models used here, the SAM Index calculated from mid-latitude $\left(40^{\circ} \mathrm{S}\right)$ zonal pressure data that is restricted to the Drake Passage sector $\left(80^{\circ} \mathrm{W}-30^{\circ} \mathrm{W}\right.$; green) is highly correlated to the SAM index derived using the full circumpolar pressure data (black). Quoted correlation coefficients ( $r$ ) are for unsmoothed annual values since $1000 \mathrm{AD}$ and all are significant at a $p<0.001$ level. 


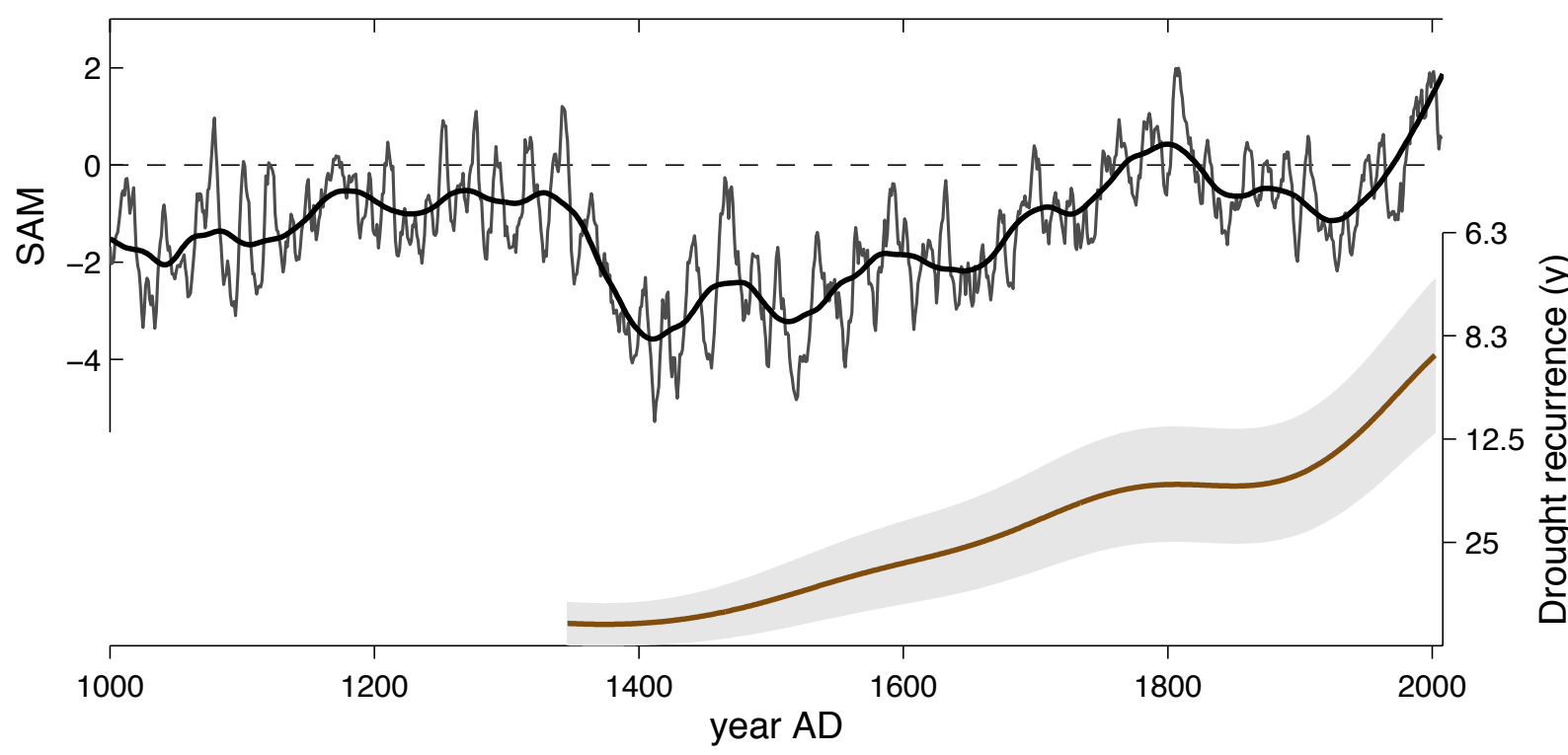

Supplementary Figure 7. SAM reconstruction, shown as 7y moving average (grey) and 70y loess filter (black) relative to 1961-1990 mean (dashed), compared with a reconstruction of the frequency of severe and extreme droughts in the Central Andes ${ }^{45}$ (brown; grey shading denotes 90\% confidence interval).

The increasing drought frequency in the central Andes since the $15^{\text {th }}$ Century is thought to reflect southward contraction of the westerly storm tracks that influence the latitudinal position of the Temperate-Mediterranean climate transition in the Central Andes ${ }^{45}$. These environmental changes are consistent with our reconstruction of positive trends in the SAM during the $16^{\text {th }}-18^{\text {th }}$ Centuries, a hiatus or reversal of the positive SAM trend during the $19^{\text {th }}$ Century, and resumption of the positive SAM trend since the early $20^{\text {th }}$ Century. 


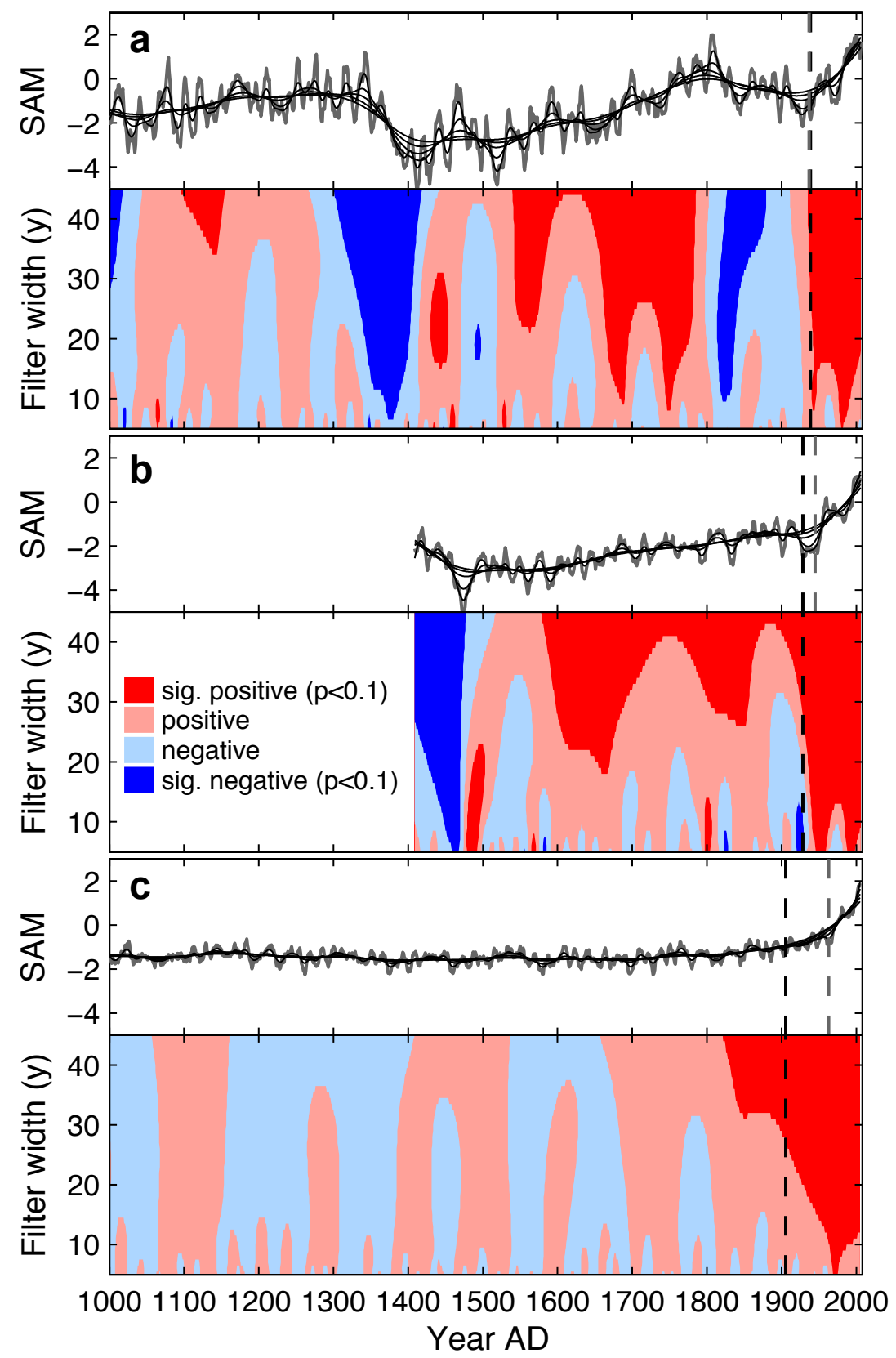

Supplementary Figure 8. Trend analysis of SAM reconstructions and simulations for the last millennium. SAM trends were analysed using the SiZer method ${ }^{17,46}$, by calculating trends at different levels of smoothing. Trend analysis was carried out on a, the weighted-CPS SAM reconstruction, the Villalba-SAM reconstruction ${ }^{37}$ and $c$, the ensemble mean of SAM in CMIP5 last millennium simulations (Figure 3a-c). Upper panels show the $7 y$ moving average of the SAM records (black) along with Gaussian kernel filters of the annual SAM records at $5 y, 10 y, 20 y, 30 y$ and $40 y$ bandwidths (grey). Lower panels map positive and negative trends in the SAM Index through time and at different levels of smoothing of the annual records. The initiation of the recent phase of significant positive SAM trends was estimated as the median changepoint timing across all filters between 15-40y bandwidths (black dashed) ${ }^{17}$. The changepoints for recent positive SAM trends were also assessed using the breakfit method ${ }^{47}$ (grey dashed), which finds the optimum intersection point for two straight-line fits to the data since $1800 \mathrm{AD}$.

Based on the SiZer method, the initiation of significant positive trends in the annual SAM Index occur at a, 1939 AD $( \pm 25 y, 1 \sigma), b, 1929$ AD ( \pm 9y) and c, 1906 AD ( \pm 42y). The initiation of significant positive SAM trends in the CMIP5 ensemble mean is highly dependent on the level of smoothing, but is more tightly constrained in the proxy-based reconstructions due to the plateau or reversal of SAM trends that is observed in the $19^{\text {th }}$ century. The breakfit method assigns the starting point for the recent linear trend in SAM at a, 1937 AD, b, 1945 AD and c, 1963 AD. 


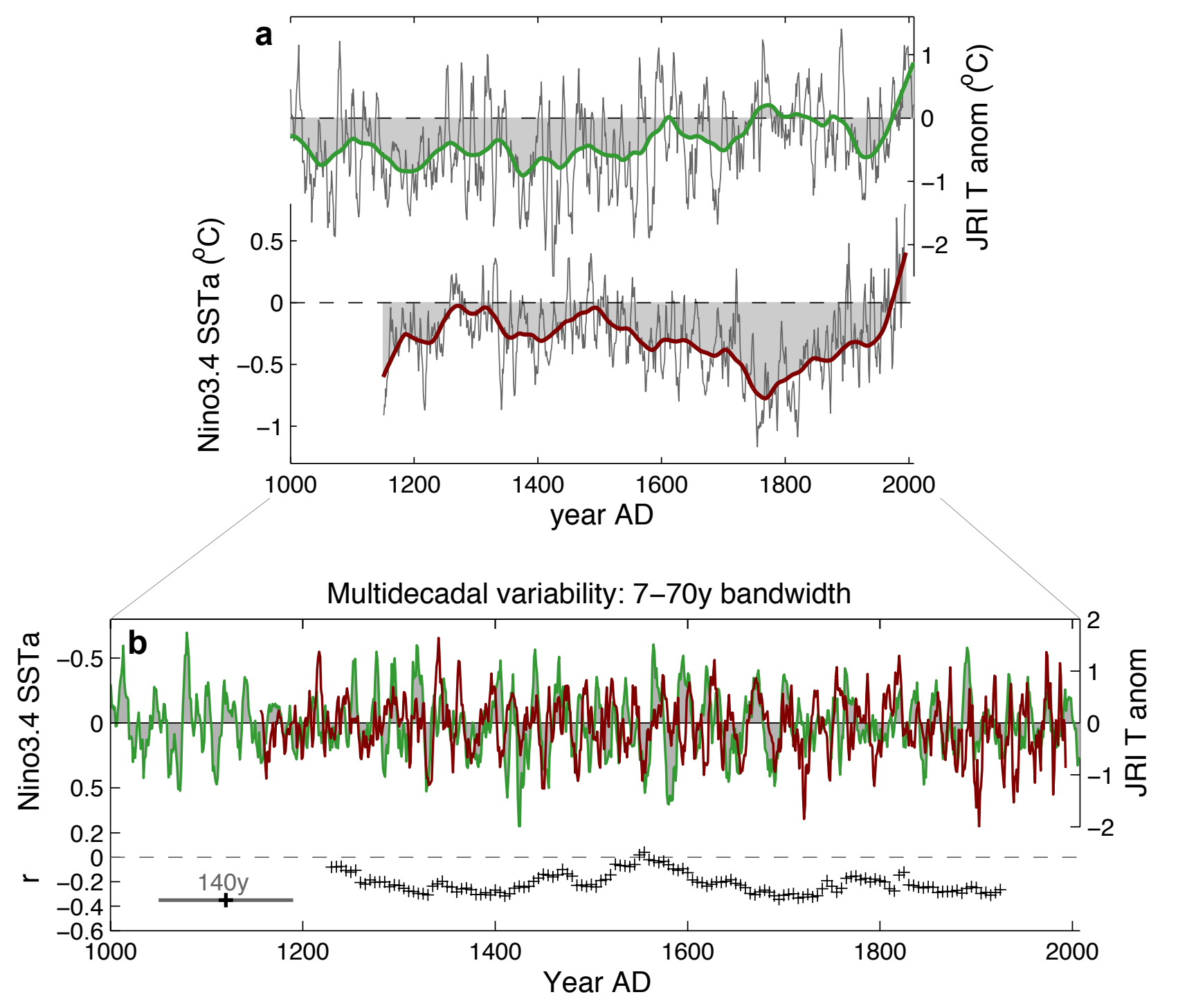

Supplementary Figure 9. ENSO teleconnections in the Antarctic Peninsula region. a, Reconstructions of Niño3.4 SST (red) ${ }^{48}$ and JRI temperature (green), shown as moving 7y averages (thin grey) and 70y loess filters (thick; grey shading) relative to 1961-1990 mean (dashed). b. Multidecadal variability in the Niño3.4 (red; inverted) and JRI (green) series, isolated using 7y moving average low-pass and 70y loess high-pass filtering. Correlation coefficient ( $r$ ) of the Niño3.4 and JRI series using moving 140y windows (black crosses).

Multidecadal climate variability on the Antarctic Peninsula over the last millennium displays the same inverse correlation with Niño3.4 SST as is seen for present-day interannual climate teleconnections (i.e. warm Niño3.4 SST corresponds with cool anomalies on the Antarctic Peninsula and negative SAM phases; Fig. 4, Table 1). Moving correlation analysis demonstrates that while there may be fluctuations in the strength of the teleconnection through time, the inverse phasing of warm Niño3.4 SST coinciding with cool Antarctic Peninsula climate at multidecadal time scales has been reasonably persistent during the last millennium.

The correlations between the JRI and Niño3.4 reconstructions are statistically significant over a range of timescales and unlikely to have occurred by chance alone (Table 1), however we note that the shared variance between the two time series is low. Based on correlation coefficients, the amount of shared variance between the JRI and Niño3.4 reconstructions is $\sim 4 \%$ for $7 \mathrm{y}$ moving averages and $\sim 14 \%$ for $70 \mathrm{y}$ moving averages. It is important to note, however, that the actual amount of shared variance between different aspects of the climate system will be masked when using proxy records due to the inherent non-climatic noise in these records. For example, Van Ommen and Morgan $^{49}$ estimated that the upper limit for correlations of Law Dome accumulation with southwest West Australian rainfall would be around $r=0.5(25 \%$ shared variance) in the presence of a perfect climate teleconnection. Likewise, we would expect that the true amount of shared variance between the ENSO and SAM climate modes over the last 1000 years is higher than that calculated based on correlation statistics from proxy records. 


\section{Supplementary References}

1 PAGES $2 \mathrm{k}$ consortium. Continental-scale temperature variability during the past two millennia. Nature Geosci 6, 339-346, doi:10.1038/ngeo1797 (2013).

2 Neukom, R. et al. Multiproxy summer and winter surface air temperature field reconstructions for southern South America covering the past centuries. Clim. Dynam. 37, 35-51, doi:10.1007/s00382010-0793-3 (2011).

3 von Gunten, L., Grosjean, M., Rein, B., Urrutia, R. \& Appleby, P. A quantitative high-resolution summer temperature reconstruction based on sedimentary pigments from Laguna Aculeo, central Chile, back to AD 850. The Holocene 19, 873-881, doi:10.1177/0959683609336573 (2009). LaMarche, V. C., Holmes, R. L., Dunwiddie, P. W. \& Drew, L. G. Tree-ring Chronologies of the Southern Hemisphere: Vol. 1: Argentina. (Laboratory of Tree-Ring Research, University of Arizona, Tuczon AZ, 1979).

5 Mundo, I. A., Junent, F. A. R., Villalba, R., Kitzberger, T. \& Barrera, M. D. Araucaria araucana treering chronologies in Argentina: spatial growth variations and climate influences. Trees 26, 443-458 (2012).

6 Villalba, R. Climatic fluctuations in northern Patagonia during the last 1000 years as inferred from tree-ring records. Quaternary Research 34, 346-360 (1990).

7 Lara, A., Villalba, R. \& Urrutia, R. A 400-year tree-ring record of the Puelo River summer-fall streamflow in the Valdivian Rainforest eco-region, Chile. Climatic Change 86, 331-356 (2008). Szeicz, J. M., Lara, A., Díaz, S. \& Aravena, J. C. in Dendrochronología en América Latina (ed Roig F) 245-270 (Editorial Nacional de Cuyo, 2000).

9 Lara, A. et al. Dendroclimatology of high-elevation Nothofagus pumilio forests at their northern distribution limit in the central Andes of Chile. Canadian Journal of Forest Research 31, 925-936 (2001).

10 Schmelter, A. in Dendrochronología en América Latina (ed Roig F) (Editorial Nacional de Cuyo, 2000).

11 Villalba, R., Leiva, J. C., Rubulls, S., Suarez, J. \& Lenzano, L. Climate, tree-ring, and glacial fluctuations in the Rio Frias Valley, Rio Negro, Argentina. Arctic and Alpine Research, 215-232 (1990). Aravena, J. C., Lara, A., Wolodarsky-Franke, A., Villalba, R. \& Cuq, E. Tree-ring growth patterns and temperature reconstruction from Nothofagus pumilio (Fagaceae) forests at the upper tree line of southern Chilean Patagonia. Revista chilena de historia natural 75, 361-376 (2002). Villalba, R., Boninsegna, J. A., Veblen, T. T., Schmelter, A. \& Rubulis, S. Recent trends in tree-ring records from high elevation sites in the Andes of northern Patagonia. Climatic Change 36, 425-454 (1997).

14 Lara, A. et al. Spatial and temporal variation in Nothofagus pumilio growth at tree line along its latitudinal range (35 degrees 40' - 55 degrees $S$ ) in the Chilean Andes. Journal of Biogeography 32 , 879-893 (2005).

15 Abram, N. J., Mulvaney, R. \& Arrowsmith, C. Environmental signals in a highly resolved ice core from James Ross Island, Antarctica. J. Geophys. Res. 116, D20116, doi:10.1029/2011jd016147 (2011). Mulvaney, R. et al. Recent Antarctic Peninsula warming relative to Holocene climate and ice-shelf history. Nature 489, 141-144 (2012).

17 Abram, N. J. et al. Acceleration of snow melt in an Antarctic Peninsula ice core during the twentieth century. Nature Geosci 6, 404-411, doi:10.1038/ngeo1787 (2013).

18 Severi, M., Udisti, R., Becagli, S., Stenni, B. \& Traversi, R. Volcanic synchronisation of the EPICA-DC and TALDICE ice cores for the last 42 kyr BP. Clim. Past 8, 509-517, doi:10.5194/cp-8-509-2012 (2012).

19 Stenni, B. et al. Eight centuries of volcanic signal and climate change at Talos Dome (East Antarctica). Journal of Geophysical Research: Atmospheres 107, ACL 3-1-ACL 3-13, doi:10.1029/2000jd000317 (2002).

20 Plummer, C. T. et al. An independently dated 2000-yr volcanic record from Law Dome, East Antarctica, including a new perspective on the dating of the 1450s CE eruption of Kuwae, Vanuatu. Clim. Past 8, 1929-1940, doi:10.5194/cp-8-1929-2012 (2012).

21 Cole-Dai, J., Mosley-Thompson, E., Wight, S. P. \& Thompson, L. G. A 4100-year record of explosive volcanism from an East Antarctica ice core. Journal of Geophysical Research: Atmospheres 105, 24431-24441, doi:10.1029/2000jd900254 (2000).

22 Mosley-Thompson, E. in Climatic Variations and Forcing Mechanisms of the Last 2000 Years Vol. 41 NATO ASI Series (eds PhilipD Jones, RaymondS Bradley, \& Jean Jouzel) Ch. 13, 263-279 (Springer Berlin Heidelberg, 1996).

23 Laluraj, C. M. et al. Nitrate records of a shallow ice core from East Antarctica: Atmospheric processes, preservation and climatic implications. The Holocene 21, 351-356, doi:10.1177/0959683610374886 (2011). 
Thamban, M. et al. Aerosol perturbations related to volcanic eruptions during the past few centuries as recorded in an ice core from the Central Dronning Maud Land, Antarctica. Curr. Sci. 91, 1200-1207 (2006).

Graf, W. et al. Stable-isotope records from Dronning Maud Land, Antarctica. Ann. Glaciol. 35, 195201, doi:10.3189/172756402781816492 (2002).

Mitchell, L. E., Brook, E. J., Sowers, T., McConnell, J. R. \& Taylor, K. Multidecadal variability of atmospheric methane, 1000-1800 C.E. Journal of Geophysical Research: Biogeosciences 116, G02007, doi:10.1029/2010jg001441 (2011).

Steig, E. J. et al. Recent climate and ice-sheet changes in West Antarctica compared with the past 2,000 years. Nature Geosci 6, 372-375, doi:10.1038/ngeo1778 (2013).

Schneider, D. P. et al. Antarctic temperatures over the past two centuries from ice cores. Geophys. Res. Lett. 33, L16707, doi:10.1029/2006gl027057 (2006). Mosley-Thompson, E., Thompson, L. G., Grootes, P. M. \& Gundestrup, N. Little Ice Age (neoglacial) paleoenvironmentalconditions at Siple Station, Antarctica. Ann. Glaciol. 14, 199-204 (1990).

Marshall, G. J. Trends in the southern annular mode from observations and reanalyses. J. Clim. 16, 4134-4143 (2003).

1 Ebisuzaki, W. A Method to Estimate the Statistical Significance of a Correlation When the Data Are Serially Correlated. J. Clim. 10, 2147-2153, doi:10.1175/1520-0442(1997)010<2147:amtets>2.0.co;2 (1997). Watanabe, S. et al. MIROC-ESM 2010: model description and basic results of CMIP5-20c3m experiments. Geosci. Model Dev. 4, 845-872, doi:10.5194/gmd-4-845-2011 (2011). Bothe, O., Jungclaus, J. H. \& Zanchettin, D. Consistency of the multi-model CMIP5/P
ensemble. Clim. Past Discuss. 9, 3789-3824, doi:10.5194/cpd-9-3789-2013 (2013). Landrum, L. et al. Last Millennium Climate and Its Variability in CCSM4. J. Clim. 26, 1085-1111, doi:10.1175/jcli-d-11-00326.1 (2013).

Schurer, A. P., Hegerl, G. C., Mann, M. E., Tett, S. F. B. \& Phipps, S. J. Separating Forced from Chaotic Climate Variability over the Past Millennium. J. Clim. 26, 6954-6973, doi:10.1175/jcli-d-1200826.1 (2013).

Phipps, S. J. et al. Paleoclimate data-model comparison and the role of climate forcings over the past 1500 years. J. Clim., doi:10.1175/jcli-d-12-00108.1 (2013).

Villalba, R. et al. Unusual Southern Hemisphere tree growth patterns induced by changes in the Southern Annular Mode. Nature Geosci 5, 793-798, doi:10.1038/ngeo1613 (2012). and future prospects. The Holocene 19, 3-49, doi:10.1177/0959683608098952 (2009). Hegerl, G. C. et al. Detection of human influence on a new, validated 1500-year temperature reconstruction. J. Clim. 20, 650-666, doi:10.1175/JCLI4011.1 (2007).

Fogt, R. L. et al. Historical SAM Variability. Part II: Twentieth-Century Variability and Trends from Reconstructions, Observations, and the IPCC AR4 Models. J. Clim. 22, 5346-5365, doi:10.1175/2009jcli2786.1 (2009). Jones, J. M. et al. Historical SAM Variability. Part I: Century-Length Seasonal Reconstructions. J. Clim. 22, 5319-5345, doi:10.1175/2009jcli2785.1 (2009).

Mann, M. E., Rutherford, S., Wahl, E. \& Ammann, C. Robustness of proxy-based climate field reconstruction methods. Journal of Geophysical Research: Atmospheres 112, D12109, doi:10.1029/2006jd008272 (2007).

43 Marshall, G., Battista, S., Naik, S. \& Thamban, M. Analysis of a regional change in the sign of the SAM-temperature relationship in Antarctica. Clim. Dynam. 36, 277-287, doi:10.1007/s00382-0090682-9 (2011).

44 Dee, D. P. et al. The ERA-Interim reanalysis: configuration and performance of the data assimilation system. Q. J. R. Meteorol. Soc. 137, 553-597, doi:10.1002/qj.828 (2011). Christie, D. A. et al. Aridity changes in the Temperate-Mediterranean transition of the Andes since ad 1346 reconstructed from tree-rings. Clim. Dynam. 36, 1505-1521, doi:10.1007/s00382-009-0723-4 (2011). Chaudhuri, P. \& Marron, J. S. SiZer for exploration of structure in curves. J. Am. Stat. Assoc. 94, 807823 (1999). Mudelsee, M. Break function regression. A tool for quantifying trend changes in climate time series. The European Physical Journal. Special Topics 174, 49-63, doi:10.1140/epjst/e2009-01089-3 (2009). Emile-Geay, J., Cobb, K. M., Mann, M. E. \& Wittenberg, A. T. Estimating Central Equatorial Pacific SST Variability over the Past Millennium. Part II: Reconstructions and Implications. J. Clim. 26, 23292352, doi:10.1175/jcli-d-11-00511.1 (2013). Western Australian drought. Nature Geosci. 3, 267-272 (2010). 